\title{
Fat and Fatty Acid Requirements and Recommendations for Infants of 0-2 Years and Children of 2-18 Years
}

\author{
Ricardo Uauy ${ }^{a, b} \quad$ Alan D. Dangour ${ }^{b}$

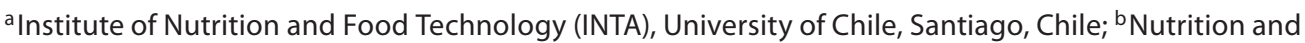 \\ Public Health Intervention Research Unit, London School of Hygiene and Tropical Medicine, London, UK
}

\section{Introduction}

Fats have traditionally been considered a necessary part of the dietary energy supply. Until recently the main focus of research has been the total amount of fat that can be tolerated and digested by infants and young children, while the composition of dietary fat had received relatively little attention. Interest in the quality of dietary lipid supply in early life as a major determinant of growth, infant development and long-term health is presently growing. Indeed, the selection of dietary fat and fatty acid sources during the first years of life is now considered to be of critical importance [Koletzko et al., 1997; Uauy et al., 2000a]. Fats enhance the taste and acceptability of foods, with lipid components determining in large part the texture, flavour and aroma of foods. In addition, fats slow gastric emptying and intestinal motility, thereby affecting satiety. Dietary lipids provide essential fatty acids (EFAs) and facilitate the absorption of lipid-soluble vitamins. Lipids are the main energy source in the infant diet and are therefore necessary for normal growth and physical activity. Indeed, fats provide around half of the energy in human milk (and in most artificial formulas). Finally, fat also constitutes the major energy store in the body; the energy content of adipose tissue on a wet weight basis is 7- to 8 -fold higher than that of tissue containing glycogen or protein.

\section{KARGER \\ Fax +4161306 1234 \\ E-Mail karger@karger.ch}

www.karger.com
(C) 2009 S. Karger AG, Basel and FAO

0250-6807/09/0553-0076\$26.00/0

Accessible online at:

www.karger.com/anm

\section{Fats and Fatty Acids in Infant and Child Nutrition}

Over recent decades interest in lipid nutrition has focused on the role of essential lipids in central nervous system development, and of specific fatty acids and cholesterol in lipoprotein metabolism. The impact of fats and fatty acids on the development of nutrition related chronic diseases throughout the life course has also received considerable attention. Lipids are structural components of all tissues and are indispensable for the assembly of membranes and cell organelles. The brain, retina and other neural tissues are particularly rich in long-chain polyunsaturated fatty acids (LCPs). Some LCPs derived from the n-6 and n-3 EFAs are precursors for eicosanoid and docosanoid production (prostaglandins, prostacyclins, thromboxanes, leukotrienes, resolvins and neuroprotectins). These autocrine and paracrine mediators are powerful regulators of physiologic functions (such as thrombocyte aggregation, inflammatory responses, leukocyte migration, vasoconstriction and vasodilatation, blood pressure, bronchial constriction, uterine contractility, apoptosis and reperfusion oxidative damage).

Dietary lipids affect cholesterol metabolism at an early age, and may be associated with cardiovascular morbidity and mortality in later life. Lipid supply, particularly EFAs and LCPs, has also been shown to affect neural development and function [Uauy and Hoffman, 1991; Uauy et al., 2000c]. Evidence indicates that specific fatty 
acids exert their effect by modifying the physical properties of membranes, including membrane-related transport systems, ion channels, enzymatic activity, receptor function and various signal transduction pathways. More recently the demonstration that specific fatty acids have a role in determining levels of gene expression for key transcription factors, peroxisome proliferator-activated receptors and retinoic acid receptors has led to increased interest in better defining the role of these critical nutrients in the regulation of lipid metabolism, energy partitioning, insulin sensitivity, adipocyte development and neural function across the lifespan [Innis, 1991; Lauritzen et al., 2001].

\section{Essential Fatty Acid Deficiency, Synthesis and Metabolism}

Burr and Burr [1929] introduced the concept that specific components of fat may be necessary for the proper growth and development of animals and possibly humans. They proposed that 3 specific fatty acids be considered as essential: linoleic acid (LA C18:2n-6), arachidonic acid (AA C20:4n-6) and $\alpha$-linolenic acid (ALA C18:3n-3). Despite this important early work, EFAs were considered of only marginal nutritional importance for humans until the 1960s, when signs of clinical deficiency were first recorded in infants fed skimmed milk-based formula [Hansen et al., 1963] and in neonates given fat-free parenteral nutrition [Caldwell et al., 1972; Paulsrud et al., 1972]. These seminal observations firmly established that LA is essential for normal infant nutrition. Hansen et al. [1963] observed dryness, desquamation and thickening of the skin and growth faltering as frequent clinical manifestations of LA deficiency in young infants. The study included 428 infants fed cow milk-based formulations with different types of fat providing a daily LA intake ranging from $10 \mathrm{mg} / \mathrm{kg}$ when fed a fully skimmed milk-based preparation to $800 \mathrm{mg} / \mathrm{kg}$ when fed a corn and coconut oil-based preparation. More subtle symptoms appear in n-3 EFA deficiency including skin changes unresponsive to LA supplementation, abnormal visual function and peripheral neuropathy have been reported in subjects receiving high $n-6$, low $n-3$ fat sources as part of their intravenous nutrition supply [Holman et al., 1982, 1988].

Humans can synthesize saturated and monounsaturated fatty acids, but they cannot synthesize the n-3 and the $n-6$ families of polyunsaturated fatty acids. The parent fatty acids of these families ALA and LA are essential fatty acids and must be present in the diet. The essentiality of $n-6$ and $n-3$ fatty acids for humans is best explained by the inability of animal tissues to introduce double bonds in positions proximal to carbon 9, counting from the methyl or ' $n$ ' terminus. Moreover, the fatty acids of these families cannot be interconverted, thereby making both n-3 and n-6 fatty acids essential. ALA and LA are converted to longer chain, more highly unsaturated fatty acids through enzymatic chain elongation and desaturation. ALA is converted to eicosapentaenoic acid (EPA C20:5n -3 ) and then to docosahexaenoic acid (DHA C22:6n-3), while LA is converted to AA. DHA is a critical component of cell membranes, especially in the brain and the retina. The high DHA relative content of cerebral cortex and retinal phospholipids supports an essential role of this n-3 fatty acid for brain and visual function [Uauy et al., 1991], and it is possible that nervous system manifestations of n-3 deficit may result from DHA deficit. AA is both a membrane component and a precursor to potent signalling molecules, the prostaglandins and leukotrienes. The review by Ratnayake and Galli on 'Fat and Fatty Acid Terminology, Methods of Analysis and Fat Digestion and Metabolism' in this issue provides the background on the biochemical pathways for conversion of ALA to DHA and LA to AA; figure 1 summarizes these metabolic conversions. The chain elongation/desaturation enzymes are shared by the n-3 and n- 6 fatty acids with competition between substrates for these enzymes [Burdge and Calder, 2005; Innis, 2005]. However, synthesis of long-chain n-6 from LA in early life seems to be more efficient than that of $n-3$ fatty acids [Koleztko et al., 1996; Salem et al., 1996].

Animal and human studies have established that brain phospholipid AA and DHA decrease, whereas n-9 and n-7 mono- and polyunsaturated fatty acids increase when subjects are fed on diets that are deficient in either LA and ALA or only n-3 fatty acids. Typically, cell membranes from animal or human tissues deficient in $n-3$ fatty acids have decreased levels of DHA and increased levels of the end product of n-6 metabolism, n-6 docosapentaenoic acid (C22:5n-6). Within the subcellular organelles, synaptosomes and mitochondria seem to be most sensitive to a low dietary $n-3$ supply, as evidenced by the relative abundance of DHA in these organelles and their change in composition in response to dietary deprivation [Galli et al., 1971].

Human neonates as young as 28 weeks' gestation and weighing $900 \mathrm{~g}$ are able to synthesize LCPs from their precursors [Carnielli et al., 1996; Salem et al., 1996; Uauy et al., 2000b]. However, this conversion is quite limited (3-5\% of a tracer dose of labelled precursors was found to be converted to LCPs over a 96-hour period [Uauy et al., 
Fig. 1. The pathways to convert LA to AA and docosapentaenoic acid, and ALA to DHA.

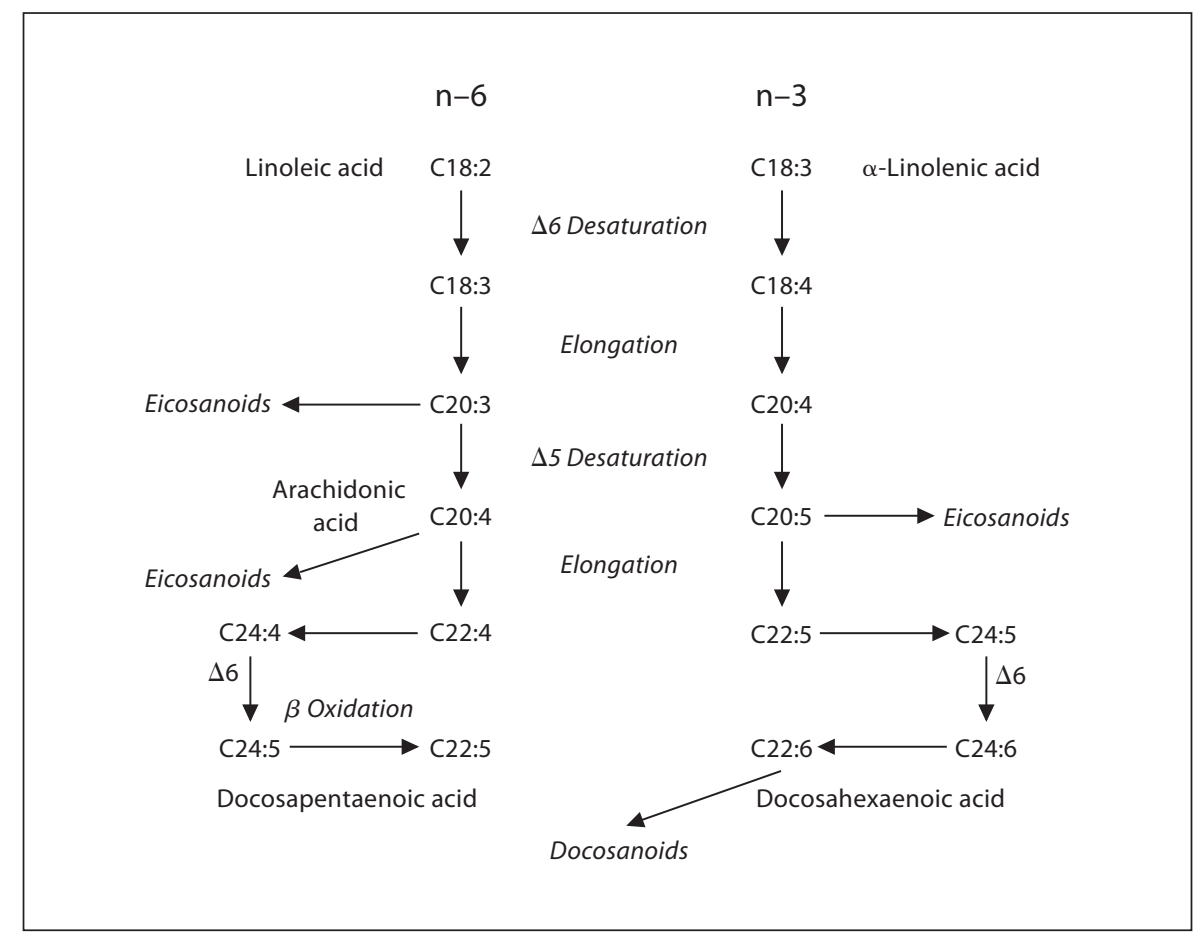

2000b], and the overall evidence indicates that in early life C18:n-3 precursors are not sufficiently converted to DHA to allow for biochemical and functional normalcy [Salem et al., 1996; Uauy et al., 2000b]. Moreover, recent studies of genetic polymorphisms in genes responsible for fatty acid desaturation suggest that variability in biochemical responses and functional central nervous system effects to changes in diet are partly explained by single nucleotide polymorphisms affecting a large proportion of the population [Schaeffer et al., 2006].

The uniqueness of the biological effects of feeding human milk on EFA metabolism is based on the direct supply of preformed LCPs, bypassing the regulatory step of both the $\Delta 6$ and $\Delta 5$ desaturases [Salem et al., 1996; Llanos et al., 2005]. Excess dietary LA associated with some vegetable oils, particularly safflower, sunflower and corn oil, may decrease the formation of DHA from ALA because the $\Delta 6$ desaturase is inhibited by excess $n-6$ substrates. In addition, on a relative conversion basis AA formation is lower when excess LA is provided. The inhibitory effect of EPA on $\Delta 5$ desaturase activity has been considered responsible for the lower membrane and plasma AA content observed when marine oil is consumed. Excess LA, as seen in infants receiving corn oil or safflower oil as the predominant fatty acid supply, will inhibit the elongation and desaturation of the parent EFAs and thus lower the
LCP supply available for membrane synthesis. Human milk and LCPs from dietary sources provide minimal preformed AA and substantial amounts of preformed n-3 LCPs such as DHA [Jensen, 1995, 1996].

LA and ALA should be considered essential and indispensable since they cannot be synthesized by humans. While DHA and AA can be synthesized from ALA and LA, respectively, they should be considered non-essential, although a dietary supply may be necessary for longterm health. However, given the limited and highly variable formation of DHA from ALA (1-5\%) and because of their critical role in normal retinal and brain development in the human they should be considered conditionally essential during early development. Similarly, they might be considered conditionally essential for life-long health considering intakes required for the prevention of cardiovascular disease [WHO/FAO, 2003].

\section{Fats and Fatty Acids as an Energy Source for Growth and Development}

On a dry weight basis, dietary triacylglycerol has the highest chemical energy value of all fuel sources (approx. $9 \mathrm{kcal} / \mathrm{g}[37.7 \mathrm{~kJ} / \mathrm{g}]$ to $4 \mathrm{kcal} / \mathrm{g}[16.8 \mathrm{~kJ} / \mathrm{g}$ ] for carbohydrates and proteins). Fat contributes approximately $35 \%$ of the 
energy required and approximately $90 \%$ of the energy retained during the first 6 months of life in a healthy infant. Infants can form saturated and monounsaturated lipids de novo for tissue deposition but the capacity for endogenous synthesis is limited. Endogenous lipid synthesis is an energy-demanding process; the synthesis of fat from glucose requires approximately $25 \%$ of the energy from glucose, whereas the storage of fat from preformed fatty acids requires only approximately $1-4 \%$ of the energy. Supply to infants of isoenergetic diets with greater content of fat than carbohydrate therefore leads to a higher weight and fat and lower energy expenditure. Obese children who consume high-fat diets tend to have a greater weight gain, whereas infants who consume low-fat diets (fat content $<25 \%$ of total energy intake) commonly fail to thrive [Tremblay et al., 1989; Brown et al., 1995; Koletzko et al., 1997].

The energy cost of growth is a major component of total energy requirements for the first 6 months of life (typically approx. $20-30 \%$ of energy), and this progressively drops in relative terms to $<5 \%$ of energy at age 12 months [Uauy et al., 2000a]. Weight gain is therefore a sensitive indicator of overall dietary energy adequacy for the first years of life [Torun et al., 1996; FAO/WHO/ UNU, 2004]. If the diet provides an adequate supply of energy and essential nutrients, there is no convincing evidence that a dietary fat intake of $30 \%$ of energy adversely affects the growth and development of healthy children living in a clean environment. A review of studies from Europe and North America also found little evidence of adverse effects of low dietary fat on growth of young children aged 6-36 months. Percentage of dietary fat was not correlated with energy intake, growth velocity or energy density of the diet between ages 6 and 12 months, whereas energy density was positively associated with energy intake and weight gain [Fjeld et al., 1989; Nicklas et al., 1992; Shea et al., 1993; Butte, 1996; Torun et al., 1996; Muñoz et al., 1997]. Dietary energy density, nutrient density and feeding frequency may be more important than dietary fat content in determining intake and growth of young children. No association between fat intake and growth was detected in infants aged 7-13 months or children aged 2-5 years or 3-5 years [Friedman et al., 1976; Lapinleimu et al., 1995; Michaelsen, 1997].

In the STRIP trial, moderately restricted fat intake (25-30\% of energy) was not associated with compromised infant growth between 7 and 36 months [Niinikoski et al., 1997]. The trial comprised 1,062 children and families when launched, and followed children from the age of 7 months to 18 years; around 600 children re-

Fat and Fatty Acid Recommendations for Infants and Children mained in the study. The intervention families received individualized dietary and lifestyle counselling at intervals of 1-6 months; the control children were exposed to standard guidance given at well-baby clinics in Finland and were seen at 12 month intervals. Dietary fat intake of the intervention children is based on predominantly poly- and monounsaturated fats while the control infants consume more saturated fats. Serum cholesterol and lowdensity lipoprotein (LDL) cholesterol values of the intervention children are significantly below those of the controls. ApoE phenotypes markedly influenced serum cholesterol values in early childhood but the intervention effects have been visible in children with all apoE types [Niinikoski et al., 1997, 2007]. These changes have occurred without changes in the growth or neurological development of the children. A similar intervention with a dietary fat intake of 30-35\% in French infants also did not result in impaired growth between ages 7 and 13 months [Michaelsen, 1995].

A number of studies have found that low-fat diets in the $25-30 \%$ range result in lower energy intakes in children with no measurable impact on growth performance, provided overall energy intake is sufficient to support maintenance, normal activity and normal tissue accretion. If the diet records accurately reflect habitual intake, these findings raise the possibility of decreased physical activity in infants and young toddlers as a way to adjust to the low-fat diets. However, several studies on secular trends, migration and vegetarian diets link dietary fat restriction to slower growth. Unfortunately, these studies are confounded by inadequacies in total energy and micronutrient intake [Rolland-Cachera et al., 1995]. Some investigators, have reported lower vitamin and mineral intakes in association with low-fat diets [Reddy et al., 1980; Zlotkin, 1996]. A cohort of 500 Canadian preschoolers was stratified according to percent of energy from fat between ages 3 and 6 years in the following groups: $<30 \%, 30-40 \%$ or $>40 \%$. Low-fat intake was associated with inadequate intake of fat-soluble vitamins. For children habitually on low-fat diets, the odds ratio for underweight for age 6 years was 2.3 [Gibson et al., 1993].

The relationship between dietary fat intake and body fat in children has been examined in a number of studies in developed countries. Unfortunately, most studies have evaluated body composition based on the measurement of skinfold thickness which is not the most sensitive predictor of total body fat. The effect of dietary fat intake on growth of 140 children in New Zealand was examined at ages 2, 4, 6 and 8 years [Boulton et al., 1995]. Median per- 
cent dietary fat intake fell from $44 \%$ at 3 months to $36 \%$ at 6 months and remained at a similar level until 8 years. At each age interval no differences were observed in height, weight or skinfold thickness among children consuming $<30,30-34.9$ and $>34.9 \%$ of dietary energy as fat. Maffeis et al. [1996] recorded a diet history and measured the skinfold thickness of 82 prepubertal Italian children. Mean fat intake was $36.6 \%$ in obese children and $33.8 \%$ in non-obese children, and percent dietary fat was only weakly correlated with percent body fat mass. Gazzaniga et al. [1993] studied 48 lean and obese American children and reported that the obese children consumed higher proportions of total energy as fat. Percent fat mass was positively correlated with dietary fat intake independent of total energy intake. Fisher and Birch [1995] found that children who preferred high-fat snacks consumed a high percentage of total energy as fat and had high triceps skinfold measurements. Ricketts [1997] obtained diet records and examined preference ratings of high- and lowfat snack foods and skinfold measurements in 88 American children, aged 9-12 years. Mean percent dietary fat was $34 \%$. Children who preferred the high-fat snacks had high dietary fat intakes. High-fat food preference was associated with higher body mass index and triceps skinfold measurements. In summary, data from industrialized countries suggest that if diet supplies adequate energy and essential nutrients, a dietary fat intake of $30 \%$ of energy is adequate for normal growth and development of healthy children. There is clearly insufficient data to firmly establish a lower and upper mean value for the population range of percent energy intake from fat. These values will clearly be context specific, depending on age, activity level, prevalence of diarrheal disease and other infectious morbidity.

The data for developing countries is much more limited. Prentice and Paul [2000] report the total fat intake of Gambian infants over their first 17 months of life, showing relatively little change in fat intake on an absolute basis and therefore a marked decline per kilogram of body weight. Fat intake was highest in the first 3 months and was provided almost entirely by human milk; as infancy progressed, an increased intake of cereal- and groundnut-based foods containing little fat replaced the gradual decline in human milk. The percent energy from fat was initially $>50 \%$ and declined to $30 \%$ by 17 months. Once infants were fully weaned at around 2 years, both fat intake and fat percent energy fell very substantially, the latter being only $15 \%$. Dietary fat was provided chiefly by groundnuts, but cereals were also important because relatively large quantities were eaten. The few fat- rich foods were those containing oil, but these expensive items were not frequently consumed. LCP intakes expressed per unit of body weight drop significantly in Gambian children after 12 months of age. These and other findings from developing nations point up clear differences in total energy and saturated fat intake between children in developed and developing countries.

\section{Cholesterol in the Infant Diet}

Interest in the long-term impact of high cholesterol feeding arose after Reiser et al. [1979] proposed that high cholesterol feeding in early life may serve to regulate cholesterol and lipoprotein metabolism in later life. Studies in suckling rats have suggested that the presence of cholesterol in the early diet may serve to define a metabolic pattern for lipoproteins and plasma cholesterol that could be of benefit later in life. Differential diets in infant baboons [Mott et al., 1991] provided evidence to the contrary in terms of benefit. Nevertheless, the observation of modified responses of adult cholesterol production rates, bile cholesterol saturation indices, and bile acid turnover, depending on whether the baboons were fed breast or formula milk served to attract further interest. The idea of possible metabolic imprinting served to trigger several retrospective and prospective studies comparing cholesterol and lipoprotein metabolism in human milk-fed and formula-fed infants. However, no long term human morbidity and mortality data supporting this notion have been reported.

Short-term human studies have been in part confounded by diversity in solid food weaning regimens, as well as varied composition of fatty acid components of the early diet; this latter factor is now known to impact circulating lipoprotein cholesterol species. The mean plasma total cholesterol by the age of 4 months in infants fed breast milk reaches $180 \mathrm{mg} / \mathrm{dl}$ or greater, while cholesterol values in formula-fed infants tend to remain under $150 \mathrm{mg} / \mathrm{dl}$. In a study by Carlson et al. [1982] infants receiving predominantly a lLA-enriched oil blend exhibited a mean cholesterol concentration of approximately $110 \mathrm{mg} / \mathrm{dl}$. A separate group of infants in the study receiving predominantly oleic acid had a mean cholesterol concentration of $133 \mathrm{mg} / \mathrm{dl}$. Infants fed breast milk and oleic acid-enriched formula had relatively higher high-density lipoprotein cholesterol and apoproteins A-I and A-II compared to the predominantly LA-enriched diet group. The ratio of (LDL + very-LDL)-cholesterol to high-density lipoprotein cholesterol was, however, lowest for in- 
fants receiving the oleic acid-predominant formula. Using a similar oleic acid-predominant formula, Darmady et al. [1972] reported a mean value of $149 \mathrm{mg} / \mathrm{dl}$ at age 4 months, compared to $196 \mathrm{mg} / \mathrm{dl}$ in a parallel breast-fed group. Most of the infants then received an uncontrolled mixed diet and cow milk, with no evident differences in plasma cholesterol levels by 12 months, independent of the type of early feeding.

Several studies have assessed the effect of feeding a controlled lipid diet on plasma cholesterol lipoprotein fractions, using a prospective randomized controlled diet design. We studied infants on controlled lipid diets from birth to age 12 months, followed by an ad libitum diet from age 12 to 24 months [Mize et al., 1995]. The experimental approach was based on the comparison of oleic acid- versus LA-predominant diets (both low in cholesterol) as compared to human milk (oleic acid-predominant and high in cholesterol). The human milk group was weaned at a mean age of 6.2 months (range 4-8.5) and after weaning received a mixed diet resembling human milk in its cholesterol content. As a result of weaning, the percent of calories delivered as fat decreased in all groups from 50 (up to age 4 months) to $35 \%$ (from ages 4 to 12 months). Our study showed significant effects of exclusive human milk feeding on lipoprotein cholesterol concentrations at 4 months. At age 9 and 12 months, the human milk group had cholesterol concentrations which were not different from those of the high oleic acid, low cholesterol diet group. The high LA, low cholesterol diet group had lower total- and LDL-cholesterol throughout the study. These data suggest that the specific fatty acid intake rather than dietary cholesterol plays a predominant role in determining total and LDL-cholesterol; this is in accordance with data from adults [Mensink and Katan, 1992].

More recently Ohlund et al. [2008] assessed the association of the quantity and quality of dietary fat intake from 6 to 12 months of age and serum lipids at 12 months in healthy term Swedish infants recruited in a longitudinal prospective study. Three hundred infants were recruited at the age of 6 months and 276 remained in the study at 12 months. The study revealed that a higher polyunsaturated fatty acid intake was associated with lower total serum cholesterol, lower LDL cholesterol and apolipoprotein B independent of total fat consumed. The results provide added support to the notion that the quality of the dietary fat has greater impact on serum lipoprotein cholesterol levels than the quantity of fat, concluding that higher polyunsaturated and lower saturated fatty acid intakes may reduce total cholesterol and LDL cholesterol early in life.

Fat and Fatty Acid Recommendations for Infants and Children

\section{Recommendations for Fat as a Proportion of the Energy Requirements of Infants}

During the first 6 months of life, dietary total fat should contribute $40-60 \%$ of total energy to cover the energy needed for growth and the fat required for tissue deposition. From age 6 months to 3 years, fat intake should be reduced gradually, depending on the physical activity of the child, to approximately $30-35 \%$ of energy, this is in line with the upper adult acceptable macronutrient distribution range. The proposed ranges are mean values for the acceptable distribution of mean energy intake from fat for a population, expressed as percent of energy.

\section{Comparison of the 1994 Recommendations and the Proposed 2008 Values}

The present recommendations differ from those of the 1994 report (0-6 months $50-60 \%$ of energy; 6 months to 3 years $30-40 \%$; children $>3$ years $30-40 \%$ ) and other recommendations formulated by national or regional expert groups (table 1). The justification for the slight decrease in lower and upper values of the acceptable range is based on the need to control energy intake more tightly in order to prevent the progression of the obesity epidemic. This at first appears to contradict the existing evidence summarized in previous sections that indicates that percent fat in the diet in early life is not associated with increased prevalence of overweight and obesity at later ages. However, the physiologic standards for energy intake [FAO/WHO/UNU, 2004] and the acceptable weight for children $0-5$ years [WHO Multicentre Growth Reference Study Group, 2006] have recently been redefined in a significant way [Uauy et al., 2006]. The new standards suggest that children after completing the first 6 months of life should gain less weight and slightly more height than previously considered, since the new standard is derived from a prescriptive approach corresponding to predominantly breast-fed infants to 6 months and non-smoking mothers. The new reference supports leaner and slightly taller children for the years $0-5$. The new energy recommendations, which are based on measured energy expenditure rather than reported energy intakes, indicate that children of 0-24 months have energy needs that are 15$20 \%$ lower than previously recommended; for children 2-6 years there was also a significant overestimation. The new norms coupled with the epidemiological evidence of a significant progression of the obesity epidemic in young children support the need to restrict the percent fat intake

Ann Nutr Metab 2009;55:76-96 
to facilitate the achievement of energy balance without undue increases in body fat. Objective controlled studies of the impact of the percent fat in the infant and child diet should be conducted in order to strengthen the evidence for this recommendation. However, in light of the public health implications of the childhood obesity epidemic and the new normative standards limiting both the upper and lower ranges of the acceptable macronutrient distribution range for fat is reasonable.

Health promotion efforts for the general population emphasize the importance of limiting the dietary intake of saturated and total fats to prevent nutrition-related chronic diseases. This has lead to a reduction of total lipid intakes in children of some populations, reaching average values as low as $28-30 \%$ energy after age 6-12 months. Adverse effects of low-fat diets ( $<25 \%$ of energy) on weight gain and longitudinal growth in young children has been documented. Lowering saturated fat but not total fat intake may be considered exclusively in children from families with evidence of dyslipidemia due to high LDL cholesterol or elevated triglyceride levels.

The total diet should provide infants with at least 3$4.5 \%$ of total energy from LA and at least $0.5 \%$ energy from ALA to meet EFA requirements. Very high intakes of EFAs have no advantage and are associated with potential health risks. Intake of LA and other $n-6$ fatty acids should be limited to $<10 \%$ of energy and intake of total polyunsaturated fatty acids should be limited to $<15 \%$ energy. After age 2 years the composition of dietary fat should be aimed at reducing the risk of nutrition-related chronic diseases: saturated fatty acid intake should not exceed $8 \%$ total energy, trans fatty acids should be maximally reduced to $<1 \%$ of total fat, polyunsaturated fatty acids should contribute approximately $6-10 \%$ of energy and the remaining fat energy should come from monounsaturated fatty acids.

The proposed values are more specific in terms of recommending maximum values for total polyunsaturated fatty acid intake and, this can be justified by the emerging information on the effect of excess $n-6$ polyunsaturated fatty acid on eicosanoid related functions and the implications for oxidative stress and chronic inflammation. The recommendation for a slightly lower percent energy from saturated fat is derived from the evidence of a beneficial effect of reduced saturated fat on LDL cholesterol plasma levels obtained in adults.

One practical approach to limiting saturated fat is to advise consumption of low-fat milk and dairy products, if this is done appropriate sources of lipid soluble vitamins (A, D and E) should be provided. Processed foods rich in hydrogenated fats should be avoided to reduce trans fatty acid intake. Unless children are very active, total fat intake should be in the range of $30-35 \%$ of total energy.

The balance in $n-6$ to $n-3$ fatty acid intake is based on eicosanoid-related effects. There are some indications that variations of the ratio of $n-6$ to $n-3$ may modulate allergy, inflammation, clotting and vascular responses. The provision of preformed LCPs has been suggested for infants not breast fed for the first 12 months of life. There is evidence for a need of preformed LCPs after weaning at age 6 months even in infants who were fully breast fed for the first 6 months of life and receive a variety of foods; the introduction of food sources of LCPs such as eggs, liver and fish are presently being delayed due to concerns about allergy.

There is a general concern that the dietary intakes of EPA and DHA among infants and children in many western and non-western countries are lower than desirable. The evidence supporting the need for $\mathrm{n}-3$ LCPs during infancy is reviewed elsewhere in this chapter. However, there is currently insufficient evidence to link increased intake levels of DHA and/or EPA to improved physical or mental development or specific functional benefits in children aged 2-18 years. Therefore, quantitative dietary intake recommendations for children cannot be established at this time. Dietary intake patterns that are advised to adults to prevent chronic diseases will apply to the whole population, including children older than 2 years of age, unless there are specific arguments for alternative guidelines or recommendations. There is no reason why children should be excluded from the advice provided to adults to consume at least 1 or 2 meals of fatty fish per week. Establishing a quantitative dietary intake recommendation for EPA and DHA for children aged 2-18 years will require a research program focussing on well-defined, public health-relevant, age-specific outcomes.

Human milk is used as a model to define acceptable intakes or other recommendations (estimated average requirement, recommended nutrient intakes) for fats and fatty acids in early life for normal infants ( $0-2$ years).

Human milk is the preferred mode of infant feeding, and present recommendations establish that term infants be exclusively breast-fed for the first 6 months of life [FAO/WHO/UNU, 2004]. The new WHO growth standards [WHO, 2006] are based on a prescription of predominant breast feeding for the first 6 months of life. Moreover, presently the evaluation of adequacy of artificial formula feeding is based on the capacity of formula to support growth, development and functional responses in a manner similar to human milk. Thus, the need to compare the biochemical, metabolic and functional re- 
sponses of breast-fed infants to those given by artificial nutrient formulations. This same paradigm has been recently used by the expert group addressing protein and amino acid requirements of children for the first 6 months of life [WHO/FAO/UNU, 2008].

Mature human milk (after the first 2-3 weeks of life) provides a fat to energy ratio of $50 \%$. Human milk provides mainly saturated (palmitic) and monounsaturated (oleic) fatty acids and a relatively high cholesterol intake of 100-150 mg/day [Jensen, 1996]. Formula-fed infants receive a similar fat to energy ratio but in contrast have a much lower cholesterol intake, $25-60 \mathrm{mg} /$ day. A mix of vegetable oils (corn, soy, safflower, olive or sunflower) is added to most formulas [Uauy et al., 2000a], and the oleic acid and LA content will depend on the oil source. The use of vegetable oils in the infant diet is based on availability, nutritional properties and relative costs of oil sources. The need to include LA, ALA and LCPs (chain length $>18$ carbons) in formulas is now well established [FAO/WHO, 1994; Uauy et al., 1999].

Human milk is a source of LA, ALA, DHA, AA, and other LCPs. The level of AA is relatively constant on a worldwide basis, while the level of DHA is more variable and depends on maternal diet and lifestyle [Agostoni et al., 1998, 2003; Marangoni et al., 2002; Smit et al., 2002; Yuhas et al., 2006]. Population means of AA in human milk range between $0.3-0.7$ weight percent of total fatty acids [Marangoni et al., 2002; Smit et al., 2002; Yuhas et al., 2006], while means of DHA range from 0.2 to $1.0 \%$ of total fatty acids [Yuhas et al., 2006]. Lactating women supplemented with DHA have an increase in milk DHA levels [Fidler et al., 2000; Jensen et al., 2005]. Gibson et al. [1997] reported that a dose-dependent response relationship exists between maternal DHA consumption and DHA levels in human milk, although human milk DHA levels $>0.8 \%$ of total fatty acids did little to increase the plasma or red blood cell DHA content of the study infants. The content of human milk EFAs and LCPs can serve to define acceptable intakes, taking into consideration the expected volume of intake, the fat content of human milk and the range of compositions measured in different regions of the world where children grow well and develop normally.

\section{Information on Blood LCP Levels Derived from Infants Not Breast Fed}

The potential use of other available information to define possible daily recommended intakes for infants (estimated average requirement, recommended nutrient in- takes, nutrient values and upper limits) [UNU/FAO/ WHO, 2007] was also explored. Dietary reference intakes for children are set using a variety of different methodological approaches, including consideration of deficiency states, usual intake levels, factorial approaches to calculate needs for maintenance and growth, and intake levels associated with impact on function and/or overall health. If no age-specific data are available extrapolation from reference values established for other age groups such as adults or interpolation from data obtained in young infants and adults are used.

Numerous studies on infants not breast fed and fed formulae with various mixtures of $\mathrm{C} 18$ polyunsaturated fatty acids, ALA and LA have been conducted in an effort to match the LCP status of breast-fed infants (as measured by plasma or red blood cell LCPs). Although DHA levels are marginally higher in infants fed formulae with a high ALA/LA ratio compared to groups fed lower ratios, they do not reach the values observed in breast-fed infants; AA levels might even be suppressed when high ALA/LA ratios are given [Chirouze et al., 1994; Jensen et al., 1996; Makrides et al., 2000]. Several studies have compared C20 and C22 LCP levels in plasma and red blood cells of infants fed human milk, formulae supplemented with LCPs or unsupplemented formula [Birch et al., 1998; Gibson et al., 1998]. Circulating levels of both DHA and AA in breast-fed infants can only be matched with the addition of both of these fatty acids to the formula. Provision of n-3 LCPs without AA in infant formula may reduce circulating AA in preterm infants [Koletzko et al., 1989; Hoffman et al., 2000; Lapillonne et al., 2000a] and in term infants [Lapillonne et al., 2000b] and may negatively affect growth in these infants [Carlson, 1996; Ryan, 1999; Lapillonne and Carlson, 2001].

\section{Effect of LCPs on Visual Development during Infancy}

Infants are born with a poorly developed visual system, but during the first year of life vision develops rapidly [SanGiovanni, 2000; Uauy, 2003]. Markers of visual development typically involve electrophysiological measures of retinal function [electroretinograms] or visual cortex function [visual evoked potential (VEP)] or behavioural measures [forced choice preferential looking(FPL)]. Methodological differences are important since electrophysiological evaluations are more sensitive than FPL, and therefore are capable of detecting smaller differences between groups. Several studies have evaluated the effect of 
Table 1. Recommendations on the dietary intake of total fat (\% of energy intake) for infants and young children according to different consultative bodies. Amended from Institute of Medicine [2005]

\begin{tabular}{lllll}
\hline & \multicolumn{2}{l}{ Age range, months } & & \\
\cline { 2 - 4 } & $0-4 / 6$ & $6-12$ & $12-24$ & $24-36$ \\
\hline AAP, 1986 & & & & $30-40 \%$ \\
AAP, 1992 & & & $30 \%$ \\
Canadian Paediatric Society, 1993 & no restriction & no restriction & no restriction & no restriction \\
European Union, 1996 & $\geq 40-58.5 \%$ & $\geq 32-58.5 \%^{\mathrm{b}}$ & & $30-35 \%$ \\
ESPGHAN, 1991 and 1994 & $\geq 40-58.5 \%$ & $\geq 32-58.5 \%^{\mathrm{a}}$ & no restriction & $30-40 \%$ \\
WHO/FAO, 1994 & $50-60 \%$ & & $30-40 \%$ & $30-40 \%$ \\
\hline
\end{tabular}

AAP = American Academy of Pediatrics Committee on Nutrition; ESPGHAN = European Society for Pediatric Gastroenterology, Hepatology and Nutrition Committee on Nutrition.

${ }^{a}$ Roy et al. [1993]. ${ }^{b}$ Recommendation for follow-on formulae only, not for total diet.

DHA status on the developing visual system although relatively few have used electroretinograms. Malcolm et al. [2003] provided fish oil to mothers during pregnancy and found that the DHA status of the infants at birth was related to the maturity of visual evoked potential at 2.5 and 6 months of age [Malcolm et al., 2003]. Eye-hand coordination at the age of 2.5 years is improved in infants whose mothers received high doses of fish oil during pregnancy [Dunstan et al., 2003]. Observational studies found that human milk DHA levels were positively correlated to visual development in breast-fed infants [Innis et al., 2001; Jorgensen et al., 2001]. Studies which evaluated lactating women receiving either an n-3 LCP supplement or a placebo control did not find a difference between groups [Gibson et al., 1997; Lauritzen et al., 2004; Jensen et al., 2005], although several studies identified a significant positive correlation between visual acuity and milk DHA levels or infant DHA status [Gibson et al., 1997; Lauritzen et al., 2004; Innis et al., 2008].

Other studies have evaluated the effect of supplementation of infant formula with LCPs on visual development with infants receiving supplemented infant formula from shortly after birth for various amounts of time. Some studies report positive results, while others find no statistically significant difference between formula groups [reviewed in SanGiovanni et al., 2000; Simmer and Patole, 2004, 2008; Fleith and Clandinin, 2005]. A number of studies reporting no positive LCP effects were conducted with very low DHA levels. Two studies have evaluated the role of formula LCPs in visual development during the second 6 months of life and both studies found improved vision when infants received LCPs during this time com- pared to infants receiving control formula [Hoffman et al., 2003; Hoffman et al., 2004], these and other studies which examined durations of LCPs supplementation suggest that they are needed at least over the first 12 months of life [Birch et al., 2002; Innis et al., 2002; Birch et al., 2005; Morale et al., 2005].

Three studies have examined the potential long-term benefits of LCPs supplemented formulae. One of these studies did not find an improvement in stereoacuity at 4-6 years of age when infants received a formula containing LCPs [Singhal et al., 2007]. A second study found no differences between breast-fed infants, or infants receiving either LCP fortified formula or control formula at 39 months of age [Auestad et al., 2003]. In the third study, infants received various formulae (control formula, formula containing DHA alone, formula containing AA and DHA), or were breast fed for 17 weeks and were assessed at 4 years of age for vision and IQ. Both vision and IQ were significantly poorer in the control group compared to breast-fed infants, while no such differences were found when the fortified formula groups were compared to the breast-fed group [Birch et al., 2007].

A recently updated Cochrane review [Simmer, 2004, 2008] did not find a significant relationship between DHA supplementation and vision or general development in infants, although the authors noted that a benefit of increased dietary LCP on information processing was possible. One problem with summary evaluation of the various studies is the wide range of LCP levels evaluated (from 0.1 weight percent DHA to $0.36 \%$ DHA). Two groups [Lauritzen et al., 2001; Uauy et al., 2003] have developed models in which infant DHA status is related to 
Table 2. Summary of current recommendations for LCP intake

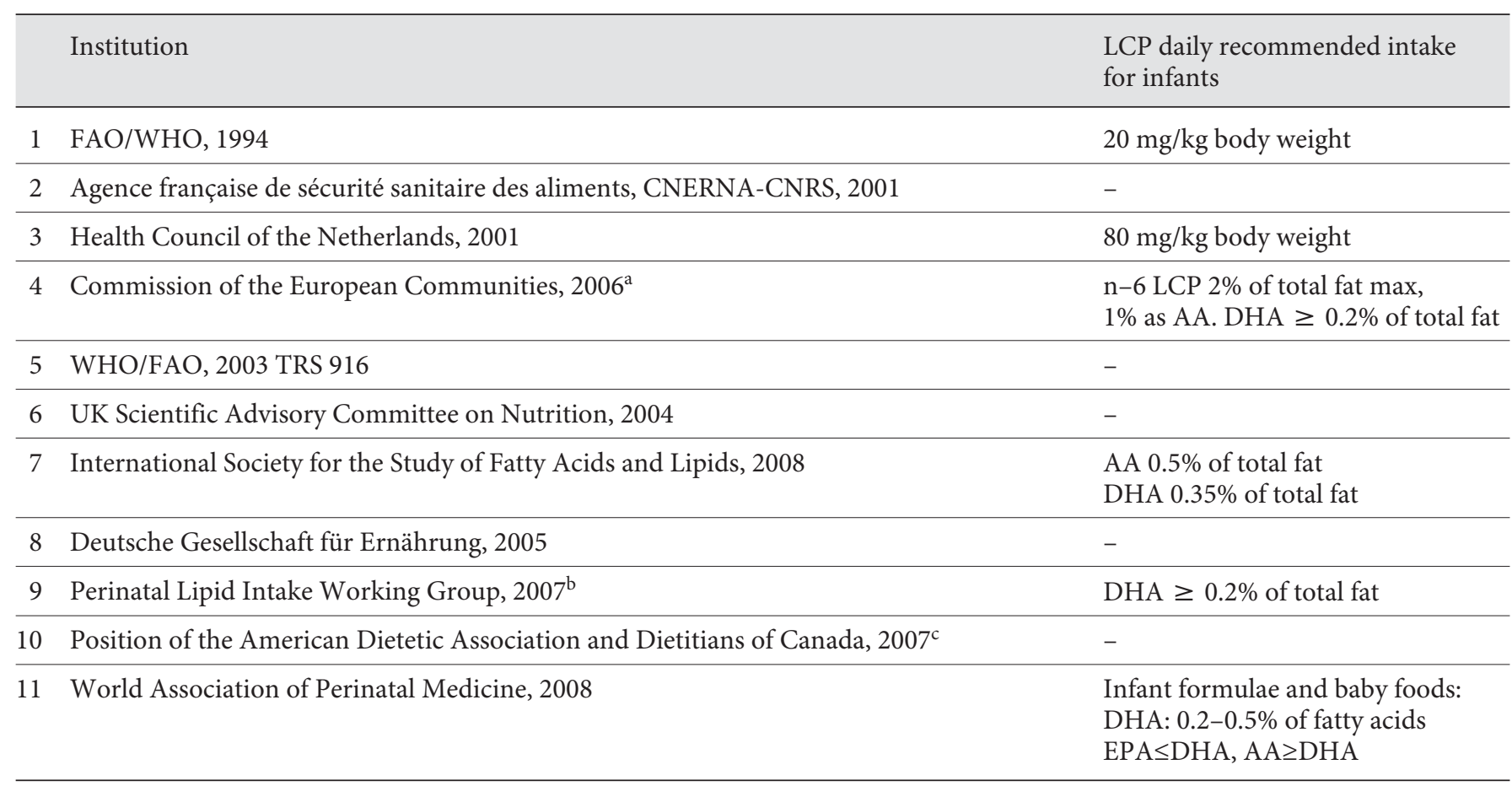

a The Commission of the European Communities. Commission Directive 2006/141/EC of 22 December 2006 on infant formulae and amending Directive 1999/21/EC. Official Journal of the European Union 30.12.2006:L401/1401/33. ${ }^{b}$ Koletzko et al. [2007]. ${ }^{c}$ Kris-Etherton et al. [2007].

dietary ALA (and subsequent conversion to DHA) and dietary DHA. Based on the meta-regression model, a positive correlation between visual development and dietary n-3 fatty acid intake was demonstrated. Mean DHAequivalent dose was directly related to size of the effect on visual acuity maturation in a comparison of 14 studies, using relative responses from each study (ratio of visual acuity observed in the experimental/control group) as the dependent variable, independent of whether VEP or FPL methods were used to assess visual maturation $\left(\mathrm{r}^{2}=0.68, \mathrm{p}<0.001\right)$, when a $10 \%$ bioequivalence factor was used for the ALA to DHA conversion.

\section{Effect of LCPs on Infant Mental Development}

Considering that the predominant $n-3$ and n-6 LCPs in the human brain are DHA and AA, it is reasonable to consider the possibility that supplementation with DHA during pregnancy and lactation, or provision of LCPs in infant formula might effect cognitive development [Clandinin et al., 1980; Farquharson et al., 1992; Martinez,
1992]. Supporting data from non-human primates are also indicative of a need for preformed DHA for normal brain development in early life [Neuringer et al., 1986; Greiner et al., 1997; Sarkadi-Nagy et al., 2003 ]. Studies have employed a variety of tests of overall mental developmental (e.g. the Bayley Scales of Infant Development) and psychomotor development (Brunet-Lezine Test), or more specific assessments such as problem solving and language development tests. Each of these measures has different components of development, therefore it is perfectly possible that some might change while others do not [Carlson and Neuringer, 1999; Wainwright, 2002; McCann and Ames, 2005]. It is also possible that responses to tests may be age specific.

Epidemiological evidence reports an association between higher levels of maternal fish consumption during pregnancy and later developmental outcomes [Oken et al., 2005; Hibbeln et al., 2007], such as higher scores of verbal intelligence quotient and other behavioural measures in children up to an age of 8 years [Hibbeln et al., 2007]. In a double blind randomized trial in Norway, maternal supplementation during pregnancy and lactation 
Table 3. Dietary composition of fat supply for children $>2$ years for prevention of nutrition-related chronic disease

\begin{tabular}{ll}
\hline Total dietary fat intake & $\begin{array}{l}30-40 \% \text { of energy depending } \\
\text { on activity }\end{array}$ \\
\hline Saturated fatty acids & $\leq 10 \%$ of energy (especially C12, \\
& C14, C16) \\
\hline Polyunsaturated fatty acids & $5-15 \%$ of energy \\
$\mathrm{n}-6$ & $4-13 \%$ of energy \\
$\mathrm{n}-3$ & $1-2 \%$ of energy \\
$\mathrm{n}-6: \mathrm{n}-3$ & $5: 1$ to $10: 1$ \\
\hline Monounsaturated fatty acids & no restriction within limits of \\
& total fat \\
\hline Cholesterol & $<$ approx. 300 mg/day \\
\hline Antioxidant vitamins & generous intake desirable \\
\hline
\end{tabular}

This dietary composition may be considered for infants $>6$ months who are at high risk of cardiovascular disease and living in a clean environment with low prevalence of infection.

with cod liver oil providing about $1.2 \mathrm{~g}$ DHA and $0.8 \mathrm{~g}$ EPA compared to a control group receiving corn oil, led to a 4-point advantage in children's scores on the Kaufmann $\mathrm{ABC}$ test in the subgroup of children tested at the age of 4 years [Helland et al., 2003] but not at age 7 years [Helland et al., 2008]. Two other studies during lactation have not demonstrated significant improvements in cognitive development [Gibson et al., 1997; Jensen, 2005] and 1 study reported a transient decrease in vocabulary comprehension at 1 year of age, but not at 2 years [Lauritzen et al., 2005].

Follow-up of breast-fed infants has demonstrated that DHA status at 2 months of age was correlated with language production and comprehension at 14 and 18 months of age [Innis et al., 2001, 2002]. Jensen et al. [2005] evaluated measures of cognitive development among infants of lactating women supplemented for 4 months after delivery with either DHA ( $200 \mathrm{mg} /$ day) or control vegetable oil. At 30 months of age, a significant increase in Bayley Psychomotor Development Index was found, although no differences were found in vision or the Bayley Mental Development Index during the study. However, controlling all the variables in evaluations of breast feeding and cognitive development is difficult.

Mixed results have been found in studies using infant formula. Some studies have demonstrated significant benefits in cognitive development when infants have received LCP containing formulae, while other studies have not [reviewed in SanGiovanni et al., 2000; Fleith et al., 2005; Eilander et al., 2007]. A Cochrane review [Simmer and Patole, 2004, 2008] found that information process- ing may be improved by dietary LCPs. In concordance with studies assessing visual acuity responses, studies using formulas with $<0.2 \%$ of total fat as DHA generally had no impact on cognitive development.

Motor development may also be influenced by early LCP supply. Spontaneous motor behaviour of infants reported as a set of parameters termed general movements, measures nervous system organization early in life. After 2 months of formula feeding with or without LCP, or breast feeding, the infants who had been randomized to be fed unsupplemented formula had a higher proportion of abnormal spontaneous general movements [Bouwstra et al., 2003]. At 18 months of age the groups did not differ in either Bayley Scales of Infant Development or Hempel scores, a standardized assessment technique for the detection of minor signs of neurological dysfunction [Bouwstra et al., 2005]. Maternal fatty acid status (measured by umbilical cord blood fatty acid analysis) and neurological development was also assessed by Bouwstra et al. At 3 months of age infants born to mothers with low AA status had significantly higher levels of abnormal general movement scores [Bouwstra et al., 2006a] and low DHA status at birth was associated with lower Hempel scores at 18 months [Bouwstra et al., 2006b]. In a randomized trial the intake of high dosages of marine oil, providing $2.2 \mathrm{~g}$ DHA and $1.1 \mathrm{~g}$ EPA per day, by women during the second half of pregnancy led to improved eye-hand coordination of the children at the age of 2.5 years [Dunstan et al., 2008]. Thus, both perinatal status and postnatal supply of LCPs may contribute to infant development.

\section{Other Health Effects of LCP Supplementation during Infancy}

Dietary supplementation of infant formula with DHA and AA has been associated with lower blood pressure at the age of 6 years [Forsyth et al., 2003]. Compared with children given unsupplemented infant formula during the first 4 months of life, those fed formula with DHA and AA had significantly lower mean blood pressure (mean difference: $-3.0 \mathrm{~mm} \mathrm{Hg}$ ) and diastolic blood pressure (mean difference: $-3.6 \mathrm{~mm} \mathrm{Hg}$ ) at 6 years of age. Since blood pressure tends to track from childhood into adult life, early exposure to dietary LCPs might have lasting effects on blood pressure and cardiovascular risk. There are also indications that early LCP supply may modulate immune response [Denburg et al., 2005; Damsgaard et al., 2007]. Infants born to atopic pregnant women who were randomized to receive a high-dosage marine oil supple- 
ment during the second half of pregnancy demonstrated an improved response to antigen skin prick test at age 1 year and less severe atopic dermatitis compared to infants whose mothers received placebo supplements [Dunstan and Prescott, 2005]. A study in preterm infants demonstrated that lymphocyte populations, cytokine production and antigen maturity were similar between infants receiving human milk and an LCP supplemented formula, while infants receiving an unsupplemented formula differed in all of these parameters [Field et al., 2000].

\section{Summary of Systematic Reviews of Data of LCP Supplementation of Term Infants}

Data on 1,719 term infants from 14 randomized controlled trials have been analysed. There was significant variation among studies regarding the type, concentration and duration of supplementation of LCPs. Variation was also noted in the outcomes measured and the methods used for assessment. Visual acuity was variously measured at 4, 6 and 12 months, and 3 years using sweep VEP, steady-state VEP and teller cards. Neuro-developmental outcomes were assessed at 3, 4, 6 and 12 months, and 2 and 3 years. In the majority of studies, neuro-developmental outcome was assessed using Bailey's scores. Physical growth was assessed at 4, 6 and 12 months, and 2 and 3 years and reported as standard physical measurements or z-scores. The various studies vary in their timing, definitions and methodologies, but the data from these randomized clinical trials do not demonstrate a clear and consistent benefit of supplementing formula with LCPs on visual acuity, neuro-developmental outcomes and physical growth in term infants [Simmer and Patole, 2004, 2008, Dunstan et al., 2008].

\section{Recommendations for LCP Intake for Term Infants Aged 0-12 Months}

The recommended method of feeding healthy infants is breast milk. The provision of a balanced dietary intake to lactating women including a regular supply of $n-3$ LCPs should ensure adequate LCP intake for the infant. The provision of dietary sources of LCPs to infants should continue for the second 6 months of life; optimal amounts cannot be specified at this time.

For formula-fed infants, considering the human milk model as the approach to define an acceptable intake for LCPs, EPA, DHA and AA should be provided as supple-
Table 4. Limits of potentially toxic factors in dietary lipids

\begin{tabular}{ll}
\hline Trans fatty acids & $<2 \%$ of total energy \\
Erucic acid & $<1 \%$ of total fat \\
Lauric and myristic acids & $<10 \%$ of total fat \\
Cyclopropenoids & trace \\
Hydroperoxides & trace
\end{tabular}

Limiting processed foods and hard fats/margarine is a practical way to limit the intake of saturated and trans fatty acids.

ments or included in infant formula. The amount of DHA provided can range from $>0.2$ to $0.5 \%$ of total fatty acids. Added AA should at be least equal in amount to that of DHA. The amount of EPA added should not exceed the amount of added DHA. These recommendations are in line with those proposed over recent years by other authoritative professionalgroups and regional expert groups as shown in table 2. The upper level for EPA + DHA should be $<1.5 \%$ of total energy. The provision of dietary sources of LCPs to infants should continue for the second 6 months of life; optimal amounts cannot be specified at this time.

\section{Potential Outcomes for the Definition of DRIs for LCPs of Normal Children Aged 2-18 Years}

Beyond infancy, evidence linking EFA and LPCs with neurological benefits is limited to special population groups with very low dietary intakes of EPA and DHA, such as children with phenylketonuria [Beblo et al., 2001, 2007]. These studies indicate that increasing DHA status with fish oil supplements is consistent with improvements in speed of information processing in the central nervous system as assessed by latencies of VEPs [Beblo et al., 2001], as well as marked improvements of coordination and fine motor skills [Beblo et al., 2007].

These findings indicate that a dietary supply of preformed DHA and/or EPA may be essential for achieving optimal neural function even in children who have a high intake of the precursor ALA. However, the possible relationship between levels of intake and effects, as well as possible other modulating factors such as genetic polymorphisms of $\Delta 6$ and $\Delta 5$ desaturases [Schaeffer et al., 2006] need to be studied in more detail in children, which appears feasible with modern non-invasive methodologies.

Intakes of EPA and DHA may also modulate the immune system by decreasing the synthesis of pro-inflam- 
matory arachidonic acid-derived eicosanoids [Calder, 2006] and by shifting the balance of Th1, Th2 and T regulatory cells [Krauss-Etschmann et al., in press]. Evidence for beneficial effects on asthma in children is not established, but some studies suggested that for certain subgroups of respondent children, symptoms of asthma may be alleviated with DHA/EPA supplementation [Broughton et al., 1997; Calder, 2006].

While regular intakes of fatty fish is widely advised to adult populations for the prevention of cardiovascular diseases (CVD) [Mozaffarian and Rimm, 2006], potential beneficial effects of EPA and DHA intakes in children on their future risk of developing CVD have not been documented. However, an individual's CVD risk profile in later in life is influenced by dietary habits in childhood [Niinikoski et al., 2007]. Elevated levels of blood risk factors at a young age will induce changes in arteries that contribute to the development of arteriosclerosis in adulthood and, furthermore, dietary habits established in early childhood may to some degree be maintained into later ages [Engler et al., 2004; Viikari et al., 2004; Hayman et al., 2007]. It is therefore conceivable that adequate intakes of EPA and DHA during childhood are important for future prevention of CVD.

EPA and DHA in combination with n-6 fatty acids have also been suggested in some studies to improve behaviour of school age children with neurodevelopmental disorders such as attention-deficit hyperactivity disorder (ADHD) and dyspraxia [Voigt et al., 2001; Richardson and Puri, 2002; Stevens et al., 2003; Hirayama et al., 2004; Richardson and Montgomery, 2005; Joshi et al., 2006; Sorgi et al., 2007, Sinn et al., 2007], aggressive behaviour [Itomura et al., 2005] and autism [Amminger et al., 2007]. However, a recent systematic review concluded that there were too many inconsistencies between studies to draw any conclusion [Ells et al., 2007].

There is currently insufficient evidence to identify an effect of LCPs on learning, education or performance of school-aged children in industrialized countries. A recent controlled study in a well-nourished school-aged population using low dose n-3 LCP (88 mg DHA and 22 mg EPA) supplementation did not find a beneficial effect on learning ability in children [Osendarp et al., 2007]. Further research is required, ideally using a randomized interventional approach, and additionally investigating the dose effects of DHA or EPA alone and in combination. The challenge in terms of interpreting the results of such studies within the context of confounders such as the family and community setting, poverty, disease and the rate of individual maturation and neurode- velopment will remain despite optimal study designs. For now, recommendations for fat and fatty acids will most likely need to follow existing dietary guidance based on prevention of cardiovascular disease as shown in table 3 .

\section{Recommendations for Dietary Intakes of Specific Essential Fatty Acids for Infants and Children}

The suggested approach is to define an acceptable intake based on observed intakes of healthy populations.

There is general concern that n-3 LCP intakes in children and adolescents tend to be low both on a unit of body weight basis and as percent of total energy [Meyer et al., 2003]. However, reliable and comparable data on dietary intake of n-3 fatty acids and on biochemical markers of status in different populations of children are scarce [Lambert et al., 2004]. The available data are insufficient to assume that increasing n-3 LCP intakes will improve physical or mental development or yield specific functional benefits relevant to the health and wellbeing of this age group.

Specific recommended levels of intake cannot be established based on age-specific data. Deriving a recommendation for children from existing recommendations for either adults or infants by extrapolation using body mass or energy expenditure has limitations since these may not adequately reflect the age-specific physiological factors that determine dietary needs.

The currently available evidence does not permit defining an age-specific quantitative estimate of recommended dietary intake for EPA and DHA for children aged 2-18 years.

However, dietary advice for children should be consistent with advice for the adult population: an intake of DHA and/or EPA equivalent to 1-2 fatty fish meals per week or approximately $500 \mathrm{mg}$ of EPA and DHA per day in order to reduce cardiovascular risk. Promoting this intake in children should also be compatible with an adequate n-3 LCP supply during pregnancy and lactation. Children aged 2-18 months in a family setting form part of the household and could thus consume at least 1 to 2 meals of fatty fish per week, which is recommended for the adult population and in agreement with the position of the American Dietetic Association and Dieticians of Canada [Kris-Etherton and Innis, 2007].
Uauy/Dangour 


\section{Recommendations for Dietary Intakes of Special Groups of Infants and Children}

\section{Preterm Infants}

This group of infants is particularly susceptible to EFA and LCP deficiency since they have very limited fat stores and greater nutrient demand given their rapid growth rate and are thus heavily dependent on dietary EFA and LCP supply for tissue accretion [Uauy et al., 1990; Carlson et al., 1993; Dobbing, 1994]. A recent Cochrane review indicates that LCP supplementation appears safe in preterm infants when growth is used as the safety parameter. Four out of 13 studies reported benefits of LCPs on growth of supplemented infants at different postnatal ages. Recent studies adding AA to the supplement have found no significant negative effect on growth. A variable of importance in studies on preterm infants is the medical complications and treatments associated with early delivery; most studies enrol only relatively healthy infants. The Cochrane review concludes that no clear long-term benefits for visual or intellectual development have been demonstrated in trials providing $n-3$ LCPs to preterm infants. The largest clinical trial on preterm infants ever conducted with over 1,000 infants has been recently completed in Australia by Smithers et al. [2008]. In this study $0.4 \%$ DHA (as percent total fat) was compared to $1.0 \%$. The data support a beneficial effect of higher DHA provision on visual acuity and improved mental development assessed by the Bayley Infant Development Scale. However, the justification to date for adding LCPs to formula is based on the need to mimic the composition of human milk and not on evidence of important clinical benefits. A supplement containing a balance of $n-3$ and n-6 LCPs is unlikely to impair the growth of preterm infants.

Further work is clearly necessary to determine the extent of the benefit of supplemental LCPs on the neurodevelopment and health outcomes of infants born preterm. Any benefit to neurodevelopment may be important to this group of infants because the mean score of the preterm infants included in these studies was 1 standard deviation lower than standardized norms.

\section{Intrauterine Growth Retardation}

LCP metabolism assessed using stable isotopes suggests lower formation of DHA in infants with intrauterine growth retardation (IUGR) compared with neonates of equivalent birth weight but shorter gestation or of similar gestation with higher weights [Uauy et al., 2000a]. IUGR term and preterm infants also appear to have a lower metabolic conversion relative to infants of the same weight who are more immature, or of a similar gestational age who are heavier [Llanos et al., 2005]. These studies complement other observations demonstrating lower LCP plasma concentrations in IUGR infants. The decrease in DHA and not in AA formation in infants with IUGR suggests that the metabolic abnormalities are related to the final metabolic steps that include the insertion of the sixth double bond and a partial $\beta$-oxidation that occurs in peroxisomes [Sprecher, 2000]; AA formation does not require the peroxisomal step. Considering the important role that DHA plays in neural and retinal development, the finding of a lower formation of DHA in infants with IUGR may have important implications as it can be a contributing factor to the abnormalities in neurodevelopment described in infants with IUGR [Llanos et al., 2005; Agostoni et al., 2008].

Further work is clearly necessary to determine the extent of the benefit of supplemental LCPs on the neurodevelopment and health outcomes of infants born with IUGR. Any benefit to neurodevelopment, cardiovascular and metabolic outcomes may be important to this group of infants because they are at risk for poor neurodevelopment, hypertension, diabetes and the metabolic syndrome.

\section{Infants and Children with Metabolic Diseases \\ (Zellweger and Phenylketonuria)}

DHA supplementation given from birth may improve DHA status and neurodevelopment of infants with some genetic metabolic disorders of peroxisomes that normally result in DHA deficiency. In addition children with PKU who are placed from birth on diets restricted in animal foods, to prevent phenylalanine excess, have low DHA status and have been shown to improve their visual electrophysiological responses with n-3 LCP supplementation. Taken together, these findings suggest a potential benefit for early nutritional interventions with DHA supplementation to improve neurologic outcome for infants with some metabolic diseases, improvements correlate with better DHA status in red blood cells and plasma [Agostoni et al., 2000; Beblo et al., 2001, 2007]. The work of Martinez et al. [1994] on 13 patients who had Zellweger syndrome demonstrated improvements in vision, muscle tone, social contact, and liver function and brain myelination after being supplemented with DHA ethyl ester (100-500 mg/day), and offers further evidence in favour of the effect of DHA supplementation in patients with DHA deficits in early life. 
Further work is clearly necessary to determine the extent of the benefit of supplemental LCPs on the neurodevelopment and health outcomes of infants born with metabolic diseases affecting EFA metabolism or utilization.

\section{Vegetarians}

Individuals that eat plentiful plant sources of fats and oils receive abundant LA and ALA but virtually no LCPs unless algae are included in the diet. Vegans and vegetarians, do have a lower EPA and DHA status than omnivores, but do not develop overt signs of deficiency [Davis and Kris-Etherton, 2003]. Higher intake levels of n-3 LCPs have been associated with a range of possible physiological benefits [Akabas and Deckelbaum, 2006], such as the improvement in neurological functions in the perinatal period [Cheatham et al., 2006], the secondary and primary prevention of CVD and the metabolic syndrome in adults [Carpentier et al., 2006; Mozaffarian and Rimm, 2006], enhanced immune function [Calder, 2006], and improved pregnancy outcomes [Makrides et al., 2006; Szajewska et al., 2006; Horvath et al., 2007]. The evidence for beneficial effects of n-3 LCPs on health outcomes of vegetarian children aged $2-18$ years is limited. Further work is clearly necessary to determine the extent of the benefit of supplemental LCPs on the neurodevelopment and health outcomes of this age group.

\section{Safety Issues When Considering Food Sources of Fats Intended for Use by Children}

The selection of fat sources for infant complementary foods must consider the safety of fat sources and not only the level of fat absorption, this is especially relevant for developing countries where fats included in foods given to young children are low-cost oils or by-products of industrial processing. Since fats are structural components of tissues, especially neural tissues, $n-3$ and n-6 essential fatty acids must be provided by the diet.

Trans fatty acids formed in the hydrogenation of $\mathrm{C} 18$ n-6 and n-3 LCPs may result in potential problems for young children since they do not serve the biological role of the corresponding EFAs. For example, if all cis$18: 2 \mathrm{n}-6$ is replaced by cis-trans-18:2n-6, it does not fulfil its role as a precursor of AA. The impairment of LCP synthesis by trans fatty acids should be considered a safety issue since EFAs are essential for infant growth and development. Animal studies demonstrate altered postnatal growth when exposed to high levels of trans fatty acids. Partially hydrogenated marine oils produced as a by product of fish meal processing have been included in complementary foods in Peru and Chile [Uauy et al., 2003b]. The trans fatty acid content of hydrogenated fish oil can be very high, on the order of $30-40 \%$, raising concerns of the long-term safety given the effects of trans acids on lipoprotein cholesterol metabolism. Diets high in trans fatty acids increase LDL cholesterol, reduce HDL cholesterol and possibly increase lipoprotein(a). Absorption of C20 and C22 fatty acids derived from hydrogenated marine oils may be less than optimal, limiting the energy provided to growing children.

The low price and longer shelf life of hydrogenated fats have been used to justify their inclusion in complementary foods and other products given to children [BeareRogers et al., 1998, Parcerisa et al., 1999]. However, this needs to be balanced against the possible long-term adverse effects of this type of fat. The European Union sets an upper limit of $4 \%$ of total fat for the trans fatty acid content of foods for infants and young children, this may need to be reconsidered in view of the present limit of $2 \%$ placed from the standpoint of cardiovascular prevention. All children should be given foods that meet acute and long-term safety standards; low price of food ingredients is desirable but should not be at the expense of compromising long-term safety of the product.

\section{Lauric and Myristic Acids}

In most developing countries, fats included in foods, even those given to young children, are low-cost by-products of industrial processing of oil seeds or of animal fats [Beare-Rogers et al., 1998] (for example, coconut oil, partially or fully hydrogenated fish oil and hydrogenated vegetable fats of low cost such as cotton oil). Coconut oil has a high content of saturated fatty acids with intermediate chain length (lauric acid and myristic acid); these fatty acids are well absorbed but induce higher plasma LDL cholesterol. Human milk has relatively low concentrations of lauric (approx. 5-7\%) and myristic acids (approx. $6-8 \%)$. Some countries have placed limits on dietary intakes of lauric and myristic acids to prevent adverse long-term cardiovascular effects, in concordance with WHO TRS 916 recommendations [WHO, 2003].

\section{Erucic Acid}

This is a long-chain monounsaturated fatty acid (trans22:1n-9) found in large amounts in wild-type rapeseed oil. Absorbed erucic acid is oxidized slowly and accumulates in the myocardium, causing myocardial lipidosis and functional abnormalities in myocardial mitochondria. These side effects are observed at high but not at low 
$(<1 \%$ of dietary fatty acids) levels of intake. Canada has developed low erucic acid rapeseed oil seeds under the registered trade name Canola [Dupont et al., 1989]. Another safety concern of oils used for complementary feeding in developing countries is the need to avoid the use of rapeseed oil with high concentrations of erucic acid [Beare-Rogers et al., 1998]. If erucic acid is not monitored, toxicity may occur which is virtually impossible to diagnose clinically. If rapeseed oil is used it should be derived from genetically low erucic acid varieties. All children should be given foods that meet acute and long-term safety standards; low price of food ingredients is desirable but should not be at the expense of compromising long-term safety of the product.

Other components of vegetable oils may have adverse effects for infants and young children. Unsaponifiable ingredients in sesame seed oil have been reported to cause allergic reactions, and cyclopropenoids in cotton seed oil impair EFA desaturation. Therefore, the use of both oils in the production of infant foods has been restricted in Europe. Another critical safety issue is the stability of oils in terms of lipid peroxidation, noticed as rancidity by smell and taste.

\section{Antioxidants as Additives}

Highly unsaturated oils such as fish oil or vegetable oils used in human foods or as animal feed require substantial amounts of synthetic antioxidants to preserve their structure and prevent rancidity. Most authorities permit the use of up to $0.1 \%$ butylated hydroxytoluene, butylated hydroxyanisole, tert-butylhydroquinone and propyl or octyl gallate as total antioxidant [Beare-Rogers et al., 1998]. This is in accordance with Codex, despite some existing concerns with the safety of synthetic antioxidants, which have led some countries to restrict their use. A specific issue in the use of processed fish oil for animal feed is the safety concern of ethoxyquine or its mixtures used as an antioxidant in the product. Ethoxyquine is a highly efficient antioxidant and anti-combustion agent but is prohibited in human food products [Parke et al., 1992]. The consumption of poultry or other animals fed fish meal or fish oil containing ethoxyquine is a safety issue that has not been addressed by present regulatory efforts. Table 4 summarizes the upper limits of toxic components associated with the fatty acid composition of foods consumed by children.

\section{Storage, Packaging and Distribution}

Safety problems may also be created by the way oils are stored, distributed and/or dispensed. Large tin or plastic barrels used in developing countries to reduce costs of distribution may facilitate adulteration of products and promote peroxidation given the large volume and the long time until the total product is sold. A study in marasmic children demonstrated altered antioxidant defence systems and increased lipid peroxidation, suggesting an increased risk of oxidative damage in malnourished infants [Mansur et al., 2000]. Bottled oil ready for consumer purchase is undoubtedly safer but is also more expensive. Soft plastic containers made with phthalic acid as plasticizer can also create safety problems because this agent is fat soluble and a known carcinogen; rigid plastics or glass bottles are preferable [Korhonen et al., 1983]. Tetra Pak brick containers have been introduced in some countries to package oils, this type of container prevents rancidity by limiting exposure to light and oxygen.

\section{Research Needs}

Further systematic research is needed to provide a sound scientific basis for formulating specific intake levels for n-3 LCPs in children aged 2-18 years. Relevant public health outcomes that are likely to be linked to lifelong intakes of EPA and DHA include future risk of cardiovascular disease and metabolic syndrome, optimal mental development and behaviour, and immune response. Dietary studies should be carefully conducted and analysed, with a specific and standardized methodology, considering the substantial challenges in assessing individual intakes of EPA and DHA in children. However, because assessment of dietary intake is always inaccurate, age-specific information on fatty acid status based on biological markers is required. Cross-sectional analyses from prospective birth and childhood cohort studies may provide valuable insights that can contribute to designing intervention trials. Age-specific effects of different fatty acid intakes and dosages on relevant endpoints should be assessed in controlled intervention studies. The data obtained should aim at establishing the effect of different doses of individual fatty acids, and of different combinations and ratios of polyunsaturated fatty acids, on well-defined and quantifiable outcomes of public health significance. Potential adverse effects of recommending increased dietary intakes of EPA and DHA or of fatty fish, such as risk of contamination with environmental pollutants or increased bleeding risks, should also be carefully assessed [Innis et al., 2006].

Ann Nutr Metab 2009;55:76-96 
Future research should consider short- and long-term effects of genetic variation in fatty acid desaturase activities and the respective effect of LCP intake prior to and during pregnancy, lactation and infancy. Studies are needed that address subgroups with potential specific needs and benefits, such as women with restricted dietary intakes, multiple or at risk pregnancies or short intervals between pregnancies. Supplementation studies should aim to examine growth, body composition and bone mineralization, visual and cognitive development, as well as effects on immune outcomes such as allergy and inflammatory disorders, and cardiovascular function. Studies evaluating different amounts of LCP, and the specific effects of AA supply, with sufficient duration of intake, adequate sample sizes, and standardized methodology for outcome measurements need careful consideration. Dose response studies of LCP intake during the second 6 months of life should be undertaken. Simplified measures of dietary supply and of LCP status that permit evaluation of large population groups including young children should be developed and evaluated.

\section{Acknowledgment}

We thank Arabella Hayter MSc, Nutrition and Public Health Research Unit, London School of Hygiene and Tropical Medicine, for providing technical assistance.

\section{Disclosure Statement}

Dr. Uauy has served as an ad-hoc technical consultant for Bristol-Myers Squibb and currently for Cadbury; in addition he serves as an ad-hoc consultant for Bimbo Mexico and Kellogg's in advising on scientific awards and prizes related to nutrition. Dr. Dangour was the Principal Investigator for the OPAL study investigating the effect of $n-3$ LCP on cognitive function in adults.

\section{References}

Agence française de sécurité sanitaire des aliments, CNERNA-CNRS: Apports nutritionnels conseillés pour la population française, ed 3. Paris, Editions Tec \& Doc, 2001.

Agostoni C, Marangoni F, Giovannini M, Riva E, Galli C: Long-chain polyunsaturated fatty acids, infant formula, and breastfeeding. (Letter) Lancet 1998;352:1703-1704.

-Agostoni C, Massetto N, Biasucci G, Rottoli A, Bonvissuto M, Bruzzese MG, et al: Effects of long-chain polyunsaturated fatty acid supplementation on fatty acid status and visual function in treated children with hyperphenylalaninemia. J Pediatr 2000;137:504-509.

-Agostoni C, Marangoni F, Grandi F, Lammardo AM, Giovannini M, Riva E, Galli C: Earlier smoking habits are associated with higher serum lipids and lower milk fat and polyunsaturated fatty acid content in the first six months of lactation. Eur J Clin Nutr 2003;57: 1466-1472.

-Agostoni C, Marangoni F, Stival G, Gatelli I, Pinto F, Risé P, Giovannini M, Galli C, Riva E: Whole blood fatty acid composition differs in term vs. mildly preterm infants: small versus matched appropriate for gestational age. Pediatr Res 2008;64:298-302.

-Akabas SR, Deckelbaum RJ: Summary of a workshop on $\mathrm{n}-3$ fatty acids: current status of recommendations and future directions. Am J Clin Nutr 2006;83:1536S-1538S.

-Amminger GP, Berger GE, et al: Omega-3 fatty acids supplementation in children with autism: a double-blind randomized, placebocontrolled pilot study. Biol Psychiatry 2007; 61:551-553

-Atkinson SA, Koletzko B: Determining lifestage groups and extrapolating nutrient in- take values (NIVs). Food Nutr Bull 2007;28: Birch EE, Garfield S, et al: Visual acuity and cogS61-S76.

Auestad N, Scott DT, et al: Visual, cognitive, and language assessments at 39 months: a followup study of children fed formulas containing long-chain polyunsaturated fatty acids to 1 year of age. Pediatrics 2003;112:e177-e183.

Beare-Rogers J, Ghafoorunissa A, Korver O, Rocquelin G, Sundram K, Uauy R: Dietary fat in developing countries. Food Nutr Bull 1998; 19:251-266.

Beblo S, Reinhardt H, Muntau AC, Mueller-Felber W, Roscher AA, Koletzko B: Fish oil supplementation improves visual evoked potentials in children with phenylketonuria. Neurology 2001;57:1488-1491.

Beblo S, Reinhardt H, et al: Effect of fish oil supplementation on fatty acid status, coordination, and fine motor skills in children with phenylketonuria. J Pediatr 2007;150:479484.

- Birch EE, Hoffman DR, Uauy R, Birch DG, Prestidge C: Visual acuity and the essentiality of docosahexaenoic acid and arachidonic acid in the diet of term infants. Pediatr Res 1998; 44:201-209.

- Birch EE, Hoffman DR, Castaneda YS, Fawcett SL, Birch DG, Uauy RD: A randomized controlled trial of long-chain polyunsaturated fatty acid supplementation of formula in term infants after weaning at 6 weeks of age. Am J Clin Nutr 2002;75:570-580.

- Birch EE, Castañeda YS, Wheaton DH, Birch DG, Uauy RD, Hoffman DR: Visual maturation of term infants fed long-chain polyunsaturated fatty acid-supplemented or control formula for 12 months. Am J Clin Nutr 2005; $81: 871-879$. nitive outcomes at 4 years of age in a doubleblind, randomized trial of long-chain polyunsaturated fatty acid-supplemented infant formula. Early Hum Dev 2007;83:279-284.

-Boulton TJC, Magarey AM: Effects of differences in dietary fat on growth, energy and nutrient intake from infancy to eight years of age. Acta Paediatr 1995;84:146-150.

- Bouwstra H, Dijck-Brouwer DA, et al: Longchain polyunsaturated fatty acids have a positive effect on the quality of general movements of healthy term infants. Am J Clin Nutr 2003;78:313-318.

- Bouwstra H, Dijck-Brouwer DJ, Boehm G, Boersma ER, Muskiet FAJ, Hadders-Algra M: Long-chain polyunsaturated fatty acids and neurological developmental outcome at 18 months in healthy term infants. Acta Paediatrica 2005;94:26-32.

- Bouwstra H, Dijck-Brouwer DJ, Decsi T, Boehm G, Boersma ER, Muskiet FAJ, Hadders-Algra M: Relationship between umbilical cord essential fatty acid content and the quality of general movements of healthy term infants at 3 months. Ped Res 2006a;59:717-722.

Bouwstra H, Dijck-Brouwer DJ, Decsi T, Boehm G, Boersma ER, Muskiet FAJ, Hadders-Algra M: Neurologic condition of healthy term infants at 18 months: positive association with venous umbilical DHA status and negative association with umbilical trans-fatty acids. Ped Res 2006b;60:1-7.

-Broughton KS, Johnson CS, Pace BK, Liebman M, Kleppinger KM: Reduced asthma symptoms with n-3 fatty acid ingestion are related to 5-series leukotriene production. Am J Clin Nutr 1997;65:1011-1017. 
-Brown KH, Sanchez-Grinan M, Perez F, Peerson JM, Ganoza L, Stern JS: Effects of dietary energy density and feeding frequency on total energy intakes of recovering malnourished children. Am J Clin Nutr 1995;62:13-18.

-Burdge GC, Calder PC: Conversion of alpha-linolenic acid to longer-chain polyunsaturated fatty acids in human adults. Reprod Nutr Dev 2005;45:581-597.

- Burr GO, Burr MM: A new deficiency disease produced by rigid exclusion of fat from the diet. J Biol Chem 1929;82:345-367.

Butte NF: Energy requirements of infants. Eur J Clin Nutr 1996;50:S24-S36.

Butte NF: Fat intake of children in relation to energy requirements. Am J Clin Nutr 2007, 72(suppl):1246S-1252S.

-Calder PC: n-3 polyunsaturated fatty acids, inflammation, and inflammatory diseases. Am J Clin Nutr 2006;83:1505S-1519S.

-Caldwell MD, Johnson HT, Othersen HB: Essential fatty acid deficiency in an infant receiving prolonged parenteral alimentation. J Pediatr 1972;81:894-898.

Carlson SE, De Voe PW, Barness LA: Effect of infant diets with different polyunsaturated to saturated fat ratios on circulating high density lipoproteins J Pediatr Gastroenterol Nutr 1982;1:303-309.

-Carlson SE, Werkman SH, Rhodes PG, Tolley EA: Visual-acuity development in healthy preterm infants: of marine-oil supplementation. Am J Clin Nutr 1993;58:35-42.

-Carlson SE, Werkman SH, Tolley EA: Effect of long-chain $\mathrm{n}-3$ fatty acid supplementation on visual acuity and growth of preterm infants with and without bronchopulmonary dysplasia. Am J Clin Nutr 1996;63:687.

-Carlson SE, Neuringer M: Polyunsaturated fatty acid status and neurodevelopment: a summary and critical analysis of the literature. Lipids 1999;34:171-178.

-Carnielli VP, Wattimena DJL, Luijendijk IHT, Boerlage A, Degenhart HJ, Sauer PJJ: The very low birth weight premature infant is capable of synthesizing arachidonic and docosahexaenoic acids from linoleic and linolenic acids. Pediatr Res 1996;40:169.

Carpentier YA, Portois L, and Malaisse WJ: n-3 Fatty acids and the metabolic syndrome. Am J Clin Nutr 2006;83:1499S-1504S.

Cheatham CL, Colombo J, Carlson SE: n-3 Fatty acids and cognitive and visual acuity development: methodological and conceptual considerations. Am J Clin Nutr 2006;83: 1458S-1466S

Chirouze V, Lapillonne A, Putet G, Salle BL: Red blood cell fatty acid composition in lowbirth-weight infants fed either human milk or formula during the first months of life. Acta Paediatr Suppl 1994;405:70-77.

-Clandinin MT, Chappell JE, Leong S, Heim T, Swyer PR, Chance GW: Extrauterine fatty acid accretion in infant brain: implication for fatty acid requirements. Early Human Devel 1980;4:131-138.
Commission of the European Communities: Commission Directive 2006/141/EC of 22 December 2006 on Infant Formulae and Amending Directive 1999/21/EC. Official J Eur Union 2006:L401/1401/33.

Damsgaard CT, Lauritzen L, et al: Fish oil supplementation modulates immune function in healthy infants. J Nutr 2007;137:10311036.

Darmady JM, Fosbrooke AS, Lloyd JK: Prospective study of serum cholesterol levels during the first year of life. Br Med J 1972;2:685688.

Davis BC, Kris-Etherton PM: Achieving optimal essential fatty acid status in vegetarians: current knowledge and practical implications. Am J Clin Nutr 2003;78:640S-646S.

Denburg JA, Hatfield HM, et al: Fish oil supplementation in pregnancy modifies neonatal progenitors at birth in infants at risk of atopy. Pediatr Res 2005;57:276-281.

Deutsche Gesellschaft für Ernährung. Nutrition Report, 2004. Bonn, DGE, 2005.

Dobbing J: The later development of the brain and its vulnerability; in Davis JA, Dobbing J (eds): Scientific Foundations of Paediatrics. 1994, London, William Heinemann Medical Books, 1994, pp 565-577.

-Dunstan JA, Mori TA, et al: Fish oil supplementation in pregnancy modifies neonatal allergen-specific immune responses and clinical outcomes in infants at high risk of atopy: a randomized, controlled trial. J Allergy Clin Immunol 2003;112:1178-1184.

Dunstan JA, Prescott SL: Does fish oil supplementation in pregnancy reduce the risk of allergic disease in infants? Curr Opin Allergy Clin Immunol 2005;5:215-221.

Dunstan JA, Simmer K, Dixon G, Prescott SL: Cognitive assessment of children at age $2 \frac{1}{2}$ years after maternal fish oil supplementation in pregnancy: a randomised controlled trial. Arch Dis Child Fetal Neonatal Ed 2008;93: F45-F50.

Dupont J, White PJ, Johnston KM, Heggtveit HA, McDonald BE, Grundy SM, Bonanome A: Food safety and health effects of Canola oil. J Am Coll Nutr 1989;8:360-375.

- Eilander A, Hundscheid DC, Osendarp SJ, Transler C, Zock PL: Effects of n-3 long chain polyunsaturated fatty acid supplementation on visual and cognitive development throughout childhood: a review of human studies. Prostaglandins Leukot Essent Fatty Acids 2007;76:189-203.

Ells LJ, Hillier FC, Summerbell CD: A systematic review of the effect of nutrition, diet and dietary change on learning, education and performance of children of relevance to UK schools. University of Teesside, School of Health \& Social Care, Canter for Food, Physical activity and Obesity Research, 2007. www.food.gov.uk/multimedia/pdfs/systemreview.pdf (accessed July 13, 2008).
Engler MM, Engler MB, Malloy M, et al: Docosahexaenoic acid restores endothelial function in children with hyperlipidemia: results from the EARLY Study. Int J Clin Pharmacol Ther 2004;42:672-679.

FAO/WHO: Fats and oils in human nutrition: FAO Food and Nutrition Paper No. 57. Rome, Food and Agriculture Organization, 1994.

FAO/WHO/UNU: Human Energy Requirements: FAO Food and Nutrition Paper No. 77. Rome, Food and Agriculture Organization, 2004.

Farquharson J, Cockburn F, Ainslie PW: Infant cerebral cortex phospholipid fatty-acid composition and diet. Lancet 1992;340: 810-813.

- Fidler N, Sauerwald T, Pohl A, Demmelmair H, Koletzko B: Docosahexaenoic acid transfer into human milk after dietary supplementation: a randomized clinical trial. J Lipid Res 2000;41:1376.

- Field CJ, Van Aerde JE, et al: Effect of providing a formula supplemented with long-chain polyunsaturated fatty acids on immunity in full-term neonates. Br J Nutr 2008;99:9199.

- Fisher JO, Birch LL: Fat preferences and fat consumption of 3- to 5-year-old children are related to parental adiposity. J Am Diet Assoc 1995;95:759-764.

-Fjeld CR, Schoeller DA, Brown KH: A new model for predicting energy requirements of children during catch-up growth developed using doubly labeled water. Pediatr Res 1989; 25:503-508.

Fleith M, Clandinin MT: Dietary PUFA for preterm and term infants: review of clinical studies. Crit Rev Food Sci and Nutr 2005;45: 205-229.

Forsyth JS, Willatts $\mathrm{P}$, et al: Long chain polyunsaturated fatty acid supplementation in infant formula and blood pressure in later childhood: follow up of a randomised controlled trial. BMJ 2003;326:953.

Friedman G, Goldberg SJ: An evaluation of the safety of a low-saturated-fat, low-cholesterol diet beginning in infancy. Pediatrics 1976; 58:655-657.

Galli C, Trzeciak HI, Paoletti R: Effects of dietary fatty acids on the fatty acid composition of brain athanolamine phosphoglyceride: reciprocal replacement of n-6 and n-3 polyunsaturated fatty acids. Biochim Biophys Acta 1971;248:449-454.

Gazzaniga JM, Burns TL: Relationship between diet composition and body fatness, with adjustment for resting energy expenditure and physical activity, in preadolescent children. Am J Clin Nutr 1993;58:21-28.

Gibson RA, Neumann MA, Makrides M: Effect of increasing breast milk docosahexaenoic acid on plasma and erythrocyte phospholipid fatty acids and neural indices of exclusively breast fed infants. Eur J Clin Nutr 1997;51: S78-S84. 
Gibson RA, Makrides M, Hawkes JS, Neumann MA, Euler AR: A randomized trial of arachidonic acid dose in formulas containing docosahexaenoicacid in term infantsin Riemersma RA, et al (eds): Essential Fatty Acids and Eicosanoids: Invited Papers from the Fourth International Congress. Champaign, AOCS Press, 1998, pp 147-153.

Gibson RS, MacDonald CA, Smit Vanderkooy PD, McLennan CE, Mercer NJ: Dietary fat patterns of some Canadian preschool children in relation to indices of growth, iron, zinc, and dietary status. J Can Diet Assoc 1993;54:33-37.

- Greiner RC, Winter J, Nathanielsz PW, Brenna JT: Brain docosahexaenoate accretion in fetal baboons: bioequivalence of dietary alphalinolenic and docosahexaenoic acids. Pediatr Res 1997;426:826-834.

Hansen AE, Wiese HF, Boelsche AN, Haggard ME, Adam DJD, Davis H: Role of linoleic acid in infant nutrition: clinical and chemical study of 428 infants fed on milk mixtures varying in kind and amount of fat. Pediatrics 1963;31:171-192.

- Hayman LL, Meininger JC, Daniels SR, McCrindle BW, Helden L, Ross J, Dennison BA, Steinberger J, Williams CL: Primary prevention of cardiovascular disease in nursing practice: focus on children and youth: a scientific statement from the American Heart Association Committee on Atherosclerosis, Hypertension, and Obesity in Youth of the Council on Cardiovascular Disease in the Young, Council on Cardiovascular Nursing, Council on Epidemiology and Prevention, and Council on Nutrition, Physical Activity, and Metabolism. Circulation 2007;116:344357.

Health Council of the Netherlands: (2001) Dietary reference intakes: energy, proteins, fats, and digestible carbohydrates. Publication No. 2001/19. The Hague, Health Council of the Netherlands, 2001.

Helland IB, Smith L, et al: Maternal supplementation with very-long-chain $n-3$ fatty acids during pregnancy and lactation augments children's IQ at 4 years of age. Pediatrics 2003;111:e39-e44.

Helland IB, Smith L, et al: Effect of supplementing pregnant and lactating mothers with $n-3$ very-long-chain fatty acids on children's IQ and body mass index at 7 years of age. Pediatrics 2008;122:e472-e479.

-Hibbeln JR, Davis JM, Steer C, Emmett P, Rogers I, Williams C, Golding J: Maternal seafood consumption in pregnancy and neurodevelopmental outcomes in childhood (ALSPAC study): an observational cohort study. Lancet 2007;369:578-585.

-Hirayama S, Hamazaki T, et al: Effect of docosahexaenoic acid-containing food administration on symptoms of attention-deficit/hyperactivity disorder - a placebo-controlled double-blind study. Eur J Clin Nutr 2004;58: 467-473.
Hoffman DR, Birch EE, Birch DG, Uauy R, Castaneda YS, Lapus MG, Wheaton DH: Impact of early dietary intake and blood lipid composition of long-chain polyunsaturated fatty acids on later visual development. J Pediatr Gastroenterol Nutr 2000;31:540-553.

Hoffman DR, Birch EE, Yolanda SC, Fawcett SL, Wheaton DH, Birch DG, Uauy R: Visual function in breast-fed term infants weaned to formula with or without long-chain polyunsaturates at 4 to 6 months: a randomized clinical trial. J Pediatr 2003;42:669.

Hoffman DR, Theuer RC, et al: Maturation of visual acuity is accelerated in breast-fed term infants fed baby food containing DHA-enriched egg yolk. J Nutr 2004;134:2307-2313.

Holman RT, Johnson SB, Hatch TF: A case of human linolenic acid deficiency involving neurological abnormalities. Am J Clin Nutr 1982;35:617-623.

Holman RT: The slow discovery of the importance of $n-3$ essential fatty acids in human health. J Nutr 1998;128:427S-433S.

Horvath A, Koletzko B, Szajewska H: Effect of supplementation of women in high-risk pregnancies with long-chain polyunsaturated fatty acids on pregnancy outcomes and growth measures at birth: a meta-analysis of randomized controlled trials. Br J Nutr 2007; 98:253-259.

Innis SM: Essential fatty acids in growth and development. Prog Lipid Res 1991;30:39-103.

Innis SM, Gilley J, Werker J: Are human-milk long-chain polyunsaturated fatty acids related to visual and neural development in breast-fed infants? J Pediatr 2001;39:532538 .

Innis SM, Gilley J, Werker J: n-3 Docosahexaenoic acid is related to measures of visual and neural development in breast-fed infants to 14 months of age. Am J Clin Nutr 2002;75: 406S.

Innis SM: Essential fatty acid transfer and fetal development. Placenta 2005;26:S70-S75.

- Innis SM, Palaty J, Vaghri Z, Lockitch G: Increased levels of mercury associated with high fish intakes among children from Vancouver, Canada. J Pediatr 2006;148:759-763.

Innis SM, Friesen RW: Essential n-3 fatty acids in pregnant women and early visual acuity maturation in term infants. Am J Clin Nutr 2008;87:548-557.

International Society for the Study of Fatty Acids and Lipids: ISSFAL statement on dietary recommendations on LCPUFA in infant formula. Prostaglandins Leukot Essent Fatty Acids 2008;78:229.

Institute of Medicine: Dietary Reference Intakes for Energy, Carbohydrate, Fiber, Fat, Fatty Acids, Cholesterol, Protein, and Amino Acids (Macronutrients). Washington, National Academies Press, 2005.

Itomura MK, Hamazaki K, et al: The effect of fish oil on physical aggression in schoolchildren: a randomized, double-blind, placebocontrolled trial. J Nutr Biochem 2005; 16: 163-171.
Jensen RG: Handbook of Milk Composition. San Diego, Academic Press, 1995.

Jensen RG: The lipids in human milk. Prog Lipid Res 1996;35:53-92.

- Jensen CL, Chen H, Fraley JK, Anderson RE, Heird WC: Biochemical effects of dietary linoleic/ $\alpha$-linolenic acid ratio in term infants. Lipids 1996;31:107-113.

Jensen CL, Voigt RG, et al: Effects of maternal docosahexaenoic acid intake on visual function and neurodevelopment in breastfed term infants. Am J Clin Nutr 2005;82:125132

Jorgensen MH, Hernell O, Hughes EL, Michaelsen KF: Is there a relation between docosahexaenoic acid concentration in mothers' milk and visual development in term infants? J Pediatr Gastro Nutr 2001;32:293-296.

Joshi K, Lad S, et al: Supplementation with flax oil and vitamin $\mathrm{C}$ improves the outcome of Attention Deficit Hyperactivity Disorder (ADHD). Prostaglandins Leukot Essent Fatty Acids 2006;74:17-21.

Koletzko B, Schmidt E, Bremer HJ, Harzer G: Effects of dietary long-chain polyunsaturated fatty acids on the essential fatty acid status of premature infants. Eur J Pediatr 1989;669675 .

Koletzko B, Decsi T, Demmelmair H: Arachidonic acid supply and metabolism in human infants born at full term. Lipids 1996;31:7983.

Koletzko B, Tsang R, Zlotkin SH, Nichols B, Hansen JW (eds): Nutrition During Infancy: Principles and practice, ed 1. Cincinnati, Digital Educational Publishing, 1997, pp 123-153.

Koletzko B, Cetin I, Brenna JT: Dietary fat intakes for pregnant and lactating women. $\mathrm{Br} \mathrm{J}$ Nutr 2007;98:873-877.

Korhonen A, Hemminki K, Vainio H: Embryotoxic effects of phtalic acid derivatives, phosphates and aromatic oils used in the manufacturing of rubber on three day chicken embryos. Drug Chem Toxicol 1983;6:191207.

Kris-Etherton PM, Innis S: Position of the American Dietetic Association and Dietitians of Canada: Dietary fatty acids. J Am Dietetic Assoc 2007;107:1599-1611.

Lambert J, Agostoni C, Elmadfa I, Hulshof K, Krause E, Livingstone B, Socha P, Pannemans D, Samartin S: Dietary intake and nutritional status of children and adolescents in $\mathrm{Eu}$ rope. Br J Nutr 2004;92(suppl 2):S147-S211.

Lapillonne A, Picaud JC, Chirouze V, Goudable J, Reygrobellet B, Claris O, Salle BL: The use of low-EPA fish oil for long-chain polyunsaturated fatty acid supplementation of preterm infants. Pediatr Res 2000a;48:835841

Lapillonne A, Brossard N, Claris O, Reygrobellet B, Salle BL: Erythrocyte fatty acid composition in term infants fed human milk or a formula enriched with a low eicosapentanoic acid fish oil for 4 months. Eur J Pediatr 2000b;159:49-53. 
-Lapillonne A, Carlson SE: Polyunsaturated fatty acids and infant growth. Lipids 2001;36:901911.

Lapinleimu H, Viikari J, Jokinen E, Salo P, Routi T, Leino A, Ronnemaa T, Seppanen R, Valimaki I, Simell O: Prospective randomised trial in 1,062 infants of diet low in saturated fat and cholesterol. Lancet 1995;345:471476.

Lauritzen L, Hansen HS, Jorgensen MH, Michaelsen KF: The essentiality of long chain n-3 fatty acids in relation to development and function of the brain and retina. Prog Lipid Res 2001;40:1-94.

- Lauritzen L, Jorgensen MH, Mikkelsen TB, Skovgaard IM, Straarup E, Olsen SF, Hoy C, Michaelsen KF: Maternal fish oil supplementation in lactation: effect on visual acuity and $n-3$ fatty acid content of infant erythrocytes. Lipids 2004;39:195-206.

- Lauritzen L, Jorgensen MH, et al: Maternal fish oil supplementation in lactation: effect on developmental outcome in breast-fed infants. Reprod Nutr Dev 2005;45:535-547.

Llanos A, Li Y, Mena P, Salem N Jr, Uauy R: Infants with intrauterine growth restriction have impaired formation of docosahexaenoic acid in early neonatal life: a stable isotope study. Pediatr Res 2005;58:735-740.

Maffeis C, Pinelli L, Schutz Y: Fat intake and adiposity in 8- to 11-year-old obese children. Int J Obes Relat Metab Disord 1996;20:170174.

-Makrides M, Neumann MA, Jeffrey B, Lien EL, Gibson RA: A randomized trial of different ratios of linoleic to alpha-linolenic acid in the diet of term infants: effects on visual function and growth. Am J Clin Nutr 2000;71: 120-129.

Makrides M, Duley L, Olsen SF: Marine oil, and other prostaglandin precursor, supplementation for pregnancy uncomplicated by preeclampsia or intrauterine growth restriction. Cochrane Database Syst Rev 2006;3: CD003402.

-Malcolm CA, McCulloch DL, et al: Maternal docosahexaenoic acid supplementation during pregnancy and visual evoked potential development in term infants: a double blind, prospective, randomised trial. Arch Dis Child Fetal Neonatal Ed 2003;88:F383F390.

-Mansur M, Tatli MM, Vural H, Koc A, Kosecik M: Altered anti-oxidant status and increased lipid peroxidation in marasmic children. Pediatr Int 2000;42:289-291.

-Marangoni F, Agostini C, Lammardo AM, Bonvissuto $M$, Giovannini $M$, Galli C, Riva E: Polyunstaturated fatty acids in maternal plasma and in breast milk. Prostaglandins Leukot Essent Fatty Acids 2002;66:535.

Martinez M: Tissue levels of polyunsaturated fatty acids during early human development. J Pediatr 1992;120:S129.
Martinez M: Polyunsaturated fatty acids in the developing human brain, red cells and plasma: influence of nutrition and peroxisomal disease. J World Rev Nutr Diet 1994;75:70.

McCann JC, Ames BN: Is docosahexaenoic acid, an n-3 long-chain polyunsatured fatty acid, required for development of normal brain function? An overview of evidence from cognitive and behavioral tests in human and animals. Am J Clin Nutr 2005;82:281-295.

Mensink RP, Katan MB: Effect of dietary fatty acids on serum lipids and lipoproteins: a meta-analysis of 27 trials. Arterioscler Thromb 1992;12:911-919.

- Meyer BJ, Mann NJ, Lewis JL, Milligan GC, Sinclair AJ, Howe PR: Dietary intakes and food sources of omega- 6 and omega- 3 polyunsaturated fatty acids. Lipids 2003;38:391-398.

Michaelsen KF, Jorgensen MH: Dietary fat content and energy density during infancy and childhood: the effect on energy intake and growth. Eur J Clin Nutr 1995;49:467-483.

Michaelsen KF: Nutrition and growth during infancy: the Copenhagen Cohort Study. Acta Paediatr 1997;(suppl)420:1-36.

- Mize CE, Uauy R, Kramer R, Benser M, Allen S, Grundy SM: Lipoprotein-cholesterol responses in healthy infants fed defined diets from ages 1 to 12 months: comparison of diets predominant in oleic acid versus linoleic acid, with parallel observations in infants fed a human milk based diet. J Lipid Res 1995;36: 1178-1187.

Morale SE, Hoffman DR, et al: Duration of longchain polyunsaturated fatty acids availability in the diet and visual acuity. Early Hum Dev 2005;81:197-203.

Mott GE, Lewis DS, McGill HC Jr: Deferred effects of pre-weaning nutrition on lipid metabolism. Ann NY Acad Sci 1991;623:7080.

Mozaffarian D, Rimm EB: Fish intake, contaminants, and human health: evaluating the risks and the benefits. JAMA 2006;296: 1885-1899.

Muñoz KA, Krebs-Smith SM, Ballard-Barbash $\mathrm{R}$, Cleveland LE: Food intakes of US children and adolescents compared with recommendations. Pediatrics 1997;100:323-329.

Nicklas TA, Webber LS, Koschak ML, Berenson GS: Nutrient adequacy of low fat intakes for children: the Bogalusa Heart Study. Pediatrics 1992;89:221-228.

- Niinikoski H, Viikari J, Rönnemaa T, Helenius $\mathrm{H}$, Jokinen E, Lapinleimu H, Routi T, Lagström H, Seppänen R, Välimäki I, Simell O: Regulation of growth of 7- to 36-month-old children by energy and fat intake in the prospective, randomized STRIP baby trial. Pediatrics 1997;100:810-816.

-Niinikoski H, Lagström H, Jokinen E, Siltala M, Rönnemaa T, Viikari J, Raitakari OT, Jula A, Marniemi J, Näntö-Salonen K, Simell O: Impact of repeated dietary counseling between infancy and 14 years of age on dietary intakes and serum lipids and lipoproteins: the STRIP study. Circulation 2007;116:1032-1040.
Neuringer M, Connor WE, Lin DS, Barstad L, Luck S: Biochemical and functional effects of prenatal and postnatal omega- 3 fatty acid deficiency on retina and brain in rhesus monkeys. Proc Natl Acad Sci USA 1986;83: 4021-4025.

Öhlund I, Hörnell A, Lind T, Hernell O: Dietary fat in infancy should be more focused on quality than on quantity. Eur J Clin Nutr 2008;62:1058-1065.

-Oken E, Wright RO, Kleinman KP, Bellinger D, Amarasiriwardena CJ, $\mathrm{Hu} \mathrm{H}$, et al: Maternal fish consumption, hair mercury, and infant cognition in a US Cohort. Environ Health Perspect 2005;113:1376-1380.

Osendarp SJ, Baghurst KI, et al: Effect of a 12month micronutrient intervention on learning and memory in well-nourished and marginally nourished school-aged children: 2 parallel, randomized, placebo-controlled studies in Australia and Indonesia. Am J Clin Nutr 2007;86:1082-1093.

Paulsrud JR, Pensler L, Whitten CF, Holman RT: Essential fatty acid deficiency in infants induced by fat-free intravenous feeding. Am J Clin Nutr 1972;25:897-904.

Parcerisa J, Codony R, Boatella J, Rafecas M: Fatty acids including trans content of commercial bakery products manufactured in Spain. J Agric Food Chem 1999;47:2040-2043.

Parke DV, Lewis DF: Safety aspects of food preservatives. Food Addit Contam 1992;9:561577.

Prentice AM, Paul AA: Fat and energy needs of children in developing countries. Am J Clin Nut 2000;72:1253S-1265S.

Ratnayake WMN, Galli C: Fat and fatty acid terminology, methods of analysis and fat digestion and metabolism: a background review paper. Ann Nutr Metab 2009;55:8-43.

Reddy V, Mohanran M: Effect of dietary fat on absorption of beta-carotene from green leafy vegetables in children. Ind J Med Res 1980; 71:53-56.

- Reiser RB, O’Brien C, Henderson GR, Morroe RW: Studies on a possible function for cholesterol in milk. Nutr Rep Intl 1979;19:835849 .

Richardson AJ, Puri BK: A randomized doubleblind, placebo-controlled study of the effects of supplementation with highly unsaturated fatty acids on ADHD-related symptoms in children with specific learning difficulties. Prog Neuropsychopharmacol Biol Psychiatry 2002;26:233-239.

Richardson AJ, Montgomery P: The OxfordDurham study: a randomized, controlled trial of dietary supplementation with fatty acids in children with developmental coordination disorder. Pediatrics 2005; 115:13601366.

Ricketts CD: Fat preferences, dietary fat intake and body composition in children. Eur J Clin Nutr 1997;51:778-781. 
Rolland-Cachera MF, Deheeger M, Akrout M, Bellisle F: Influence of macronutrients on adiposity development: a follow up study of nutrition and growth from 10 months to 8 years of age. Int J Obes 1995;19:573-578.

Roy CC, Beare-Rogers J, Chappell J, Gibson R, Spady DW, Wile H, Bush M, Cheney MC, Nierlsen H (eds): Dietary Fat and Children. Ottawa, Canadian Paediatric Society and Health Canada, 1993.

Ryan AS, Montalto MB, Groh-Wargo S, Mimouni F, Sentipal-Walerius J, Doyle J, Siegman JS, Thomas AJ: Effect of DHA-containing formula on growth of preterm infants to 59 weeks postmenstrual age. Am J Hum Biol 1999;11:457-467.

- Salem N Jr, Wegher B, Mena P, Uauy R: Arachidonic and docoahexaenoic acids are biosynthesized from their 18-carbon precursors in human infants. Proc Natl Acad Sci USA 1996;93:49-54.

-SanGiovanni JP, Berkey CS, Dwyer JT, Colditz GA: Dietary essential fatty acids, long-chain polyunsaturated fatty acids and visual resolution acuity in healthy fullterm infants: a systematic review. Early Human Dev 2000; $57: 165-188$

-Sarkadi-Nagy E, Wijendran V, Diau GY, Chao AC, Hsieh AT, Turpeinen A, Nathanielsz PW, Brenna JT: The influence of prematurity and long chain polyunsaturate supplementation in 4-week adjusted age baboon neonate brain and related tissues. Pediatr Res 2003 54:244-252.

- Schaeffer L, Gohlke H, Muller M, Heid IM, Palmer LJ, Kompauer I, Demmelmair H, Illig T, Koletzko B, Heinrich J: Common genetic variants of the FADS1 FADS2 gene cluster and their reconstructed haplotypes are associated with the fatty acid composition in phospholipids. Hum Mol Genet 2006; 15: 1745.

-Shea S, Basch CE, Stein AD, Contento IR, Irigoyen $\mathrm{M}$, Zybert P: Is there a relationship between dietary fat and stature or growth in children three to five years of age? Pediatrics 1993;92:579-586.

Simmer K, Patole S: Longchain polyunsaturated fatty acid supplementation in infants form at term. Cochrane Database Syst Rev 2004;1: CD000375; update in Cochrane Database Syst Rev 2008;1:CD000375.

- Singhal A, Morley R, Cole TJ, Kennedy K, Sonksen P, Isaacs E, Fewtrell M, Elias-Jones A, Stephenson T, Lucas A: Infant nutrition and stereoacuity at age 4-6 year. Am J Clin Nutr 2007;85:152-159.

-Sinn N, Bryan J: Effect of supplementation with polyunsaturated fatty acids and micronutrients on learning and behavior problems associated with child ADHD. J Dev Behav Pediatr 2007;28:82-91.

- Smit EN, Martini IA, Mulder H, Boersma ER, Muskiet FE: Estimated biological variation of the mature human milk fatty acid composition. Prostaglandins Leukot Essent Fatty Acids 2002;66:549. mithers LG, Gibson RA, McPhee A, Makrides M: Higher dose of docosahexaenoic acid in the neonatal period improves visual acuity of preterm infants: results of a randomized controlled trial. Am J Clin Nutr 2008;88: 1049-1056.

Sorgi PJ, Hallowell EM, et al: Effects of an openlabel pilot study with high-dose EPA/DHA concentrates on plasma phospholipids and behavior in children with attention deficit hyperactivity disorder. Nutr J 2007;6:16.

Sprecher H: Metabolism of highly unsaturated n-3 and n-6 fatty acids. Biochim Biophys Acta 2000;1486:219-231.

-Stevens L, Zhang W, Peck L, Kuczek T, Grevstad N, Mahon A, Zentall SS, Arnold LE, Burgess JR: EFA supplementation in children with inattention, hyperactivity, and other disruptive behaviors. Lipids 2003;38:1007-1021.

Szajewska H, Horvath A, Koletzko B: Effect of n-3 long-chain polyunsaturated fatty acid supplementation of women with low-risk pregnancies on pregnancy outcomes and growth measures at birth: a meta-analysis of randomized controlled trials. Am J Clin Nutr 2006;83:1337-1344.

- Torun B, Davies PS, Livingstone MB, Paolisso M, Sackett R, Spurr GB: Energy requirements and dietary energy recommendations for children and adolescents 1 to 18 years old. Eur J Clin Nutr 1996;50(suppl 1):S37-S80.

Tremblay A, Plourde G, Despres JP, Bouchard C: Impact of dietary fat content and fat oxidation on energy intake in humans. Am J Clin Nutr 1989;49:799-805.

Uauy RD, Birch DG, Birch EE, Tyson JE, Hoffman DR: Effect of dietary omega-3 fatty acids on retinal function of very-low-birth-weight neonates. Pediatr Res 1990;28:485-492.

- Uauy R, Hoffman DR: Essential fatty acid requirements for normal eye and brain development. Semin Perinatol 1991;15:449-455.

Uauy R, Mena P, Valenzuela A: Essential fatty acids as determinants of lipid requirements in infants, children and adults. Eur J Clin Nutr 1999;53(suppl 1):S66-S77.

Uauy R, Mize C, Castillo-Durán C: Fat intake during childhood: metabolic responses and effects on growth. Am J Clin Nutr 2000a; 72(suppl):354S-360S.

- Uauy R, Mena P, Wegher B, Nieto S, Salem N Jr: Long chain polyunsaturated fatty acid formation in neonates: effect of gestational age and intrauterine growth. Pediatr Res 2000b;47:127.

Uauy R, Mena P, Rojas C: Essential fatty acids in early life: structural and functional role. Proc Nutr Soc 2000c;59:3-15.

Uauy R, Hoffman D, Mena P, Llanos A, Birch E: Term infant studies of DHA and ARA supplementation on neurodevelopment: results of randomized controlled trials. J Pediatr 2003a;143:S17-S25.
Uauy R, Castillo C: Lipid requirements of infants: Implications for nutrient composition of fortified complementary foods. J Nutr 2003b;133:2962S-2972S.

- Uauy R, Rojas J, Corvalan C, Lera L, Kain J: Prevention and control of obesity in preschool children: importance of normative standards. J Pediatr Gastroenterol Nutr 2006; 43(suppl 3):S26-S37.

UK Scientific Advisory Committee on Nutrition: (2004) Advice on fish consumption: benefits and risks. London, TSO, 2004.

UNU/FAO/WHO: International harmonization of approaches for developing nutrient-based dietary standards. Food Nutr Bull 2007;28: S27-S37.

Viikari JS, Niinikoski H, Juonala M, Raitakari OT, Lagstrom H, Kaitosaari T, Ronnemaa T, Simell O: Risk factors for coronary heart disease in children and young adults. Acta Paediatr Suppl 2004;93:34-42.

-Voigt RG, Llorente AM, Jensen CL, Fraley JK, Berretta MC, Heird WC: A randomized, double-blind, placebo-controlled trial of docosahexaenoic acid supplementation in children with attention-deficit/hyperactivity disorder. J Pediatr 2001;139:189-196.

Wainwright PE: Dietary essential fatty acids and brain function: a developmental perspective on mechanisms. Proc Nutr Soc 2002;61:6169.

WHO Child Growth Standards: www.who.int/ childgrowth/en (accessed September 12, 2006).

-WHO Multicentre Growth Reference Study Group: WHO child growth standards based on length/height, weight and age. Acta Paediatr Suppl 2006;450:76

WHO World Health Assembly: Infant and young child nutrition. WHA 54.2, Geneva, 2001.

WHO/FAO: Diet, nutrition and the prevention of chronic diseases: report of a joint $\mathrm{WHO} /$ FAO expert consultation. TRS 916, Geneva, 2003.

WHO/FAO/UNU Human Protein and Aminoacid Requirements and Recommendations. Geneva, WHO, 2008.

World Association of Perinatal Medicine. Koletzko B, Lien E, Agostoni C, Böhles H, Campoy C, Cetin I, Decsi T, Dudenhausen JW, Dupont C, Forsyth S, Hoesli I, Holzgreve W, Lapillonne A, Putet G, Secher NJ, Symonds M, Szajewska H, Willatts P, Uauy R; Dietary Guidelines Working Group: The roles of long-chain polyunsaturated fatty acids in pregnancy, lactation and infancy: review of current knowledge and consensus recommendations. J Perinat Med 2008;36:5-14.

-Yuhas R, Pramuk K, Lien EL: Human milk fatty acid composition from nine countries varies most in DHA. Lipids 2006;41:851-858.

Zlotkin SH: A review of the Canadian 'Nutrition recommendations update: dietary fat and children'. J Nutr 1996;126(4 suppl):1022S1027S. 